This reort contains infomation of a prelima prepared primarly for interal useat the originating intallation. $I$ is to to o to not

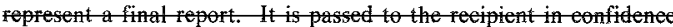
and be ab of futher diselos without the applat of the originating instlation OWDOE Offiee of Scientifie and To mient Inform, Oak Ridge, TN 37830.
ANL - IFR -35

TI86 025970

METALLOGRAPHIC CHARACTERIZATION OF UNIRRADIATED U-PU-Zr FUEL

by

R. V. Strain and J.E. Sanecki

Argonne National Laboratory

9700 South Cass Avenue

Argonne, Illinois 60439

\title{
APPLIED TECHNOLOGY
}

Any Further Dasinbution by any Holder of this Decument or of the Date Theran to Third Partes Represening Foreng interests. Forengn Governments, Foregn Com=

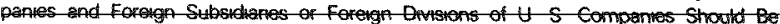
Coordinated the Deputy Assistant Secretary for Heactor Systorns, Devetopment and Technology, Department of Energy

IFR TECHNICAL MEMORANDUM NO. 35

\begin{abstract}
Results reported in the IFR-TM series of memoranda frequently are preliminary and subject to revision. consequent ly they should not be quoted op referenced without the authop's permission.
\end{abstract}

\section{NO ACCESS RESTRICTIONS}

This document is not considered OUO-Applied Technology. It was reviewed for Export Controlled Information and found to be suitable for unlimited access and reproduction.

This label reflects Applied Technology instructions issued April 13, Any 2006, by the the Department of Energy Office of Nuclear Energy. there Additional guidance has also been provided by DOE in 2016 and 2018

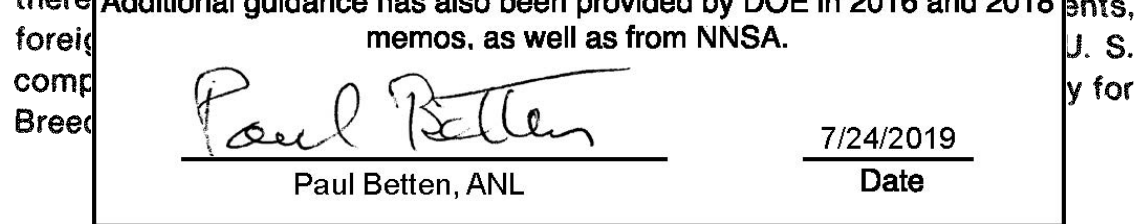

DISCLAIMER

This report was prepared as an account of work sponsored by an agency of the United States Government. Neither the United States Government nor any agency thereof, nor any of their employees, makes any warranty, express or implied, or assumes any legal liability or responsibility for the accuracy, completeness, or usefulness of any information, apparatus, product, or process disclosed, or represents that its use would not infringe privately owned rights. Reference herein to any specific commercial product, process, or service by trade name, trademark, manufacturer, or otherwise does not necessarily constitute or imply its endorsement, recommendation, or favoring by the United States Government or any agency thereof. The views and opinions of authors expressed herein do not necessarily state or reflect those of the United States Government or any agency thereof.

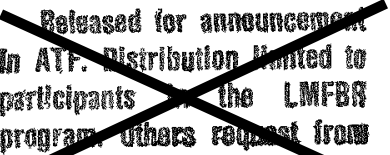

No1. DUE. 


\section{DISCLAIMER}

Portions of this document may be illegible in electronic image products. Images are produced from the best available original document. 
TABLE OF CONTENTS

Page

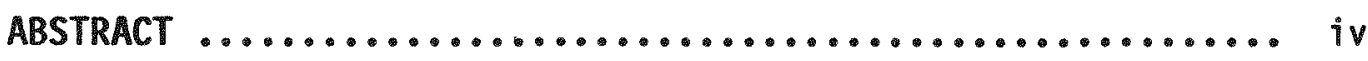

I. INTRODUCTION $\ldots \ldots \ldots \ldots \ldots \ldots \ldots \ldots \ldots \ldots \ldots \ldots \ldots \ldots \ldots \ldots \ldots \ldots$.

II. SAMPLE DESCRIPTION ................................ 2

III. GENERAL FEATURES OF THE SAMPLES $\ldots \ldots \ldots \ldots \ldots \ldots \ldots \ldots \ldots \ldots$

A. Globular Phase Distribution ..................... 5

B. Surface Layers ................................ 12

C. Grain Boundaries and Other Features .............. 17

IV. MICRO-CHEMISTRY OF THE SAMPLES .................. 23

A. SEM-EDX $\ldots \ldots \ldots \ldots \ldots \ldots \ldots \ldots \ldots \ldots \ldots \ldots \ldots \ldots \ldots \ldots \ldots \ldots \ldots \ldots \ldots$

B. SAM Analys is of the Surface Layer .................. 26

C. SAM Analysis of the Globular Phase ................ 26

D. SAM Analysis of the Matrix ......................... 31

v. DISCUSSION ................................... 31

VI. CONCLUSIONS ....................................... 33

REFERENCES .................................... 35 


\section{LIST OF FIGURES}

No. Title Page

1. Typical Casting Defects in the Current U-Pu-Zr Fuel Pin ..... 7

2. Typical Examples of the Globular Phase: Top of the Pin from Casting Batch EFL-029 ............................. 8

3. Typical Examples of the Globular Phase: Bottom of the Pin from Casting Batch EFL-029 ........................ 9

4. Strips Across Selected Samples at Approximated 100X ........ 10

5. Microstructure of the Fuel Near the Edge of the Sample and the Layer on the Surface Near the Top of the Pin from Batch EFL-029 ......................................13

6. Microstructure of the Fuel Near the Edge of the Sample and the Layer on the Surface Near the Bottom of the Pin from Batch

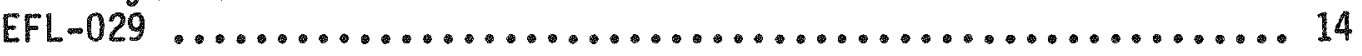

7. Surface Layer on Bottom Samples from Casting Batch EFL-031 ... 15

8. Surface Layer on Bottom Samples from Casting Batch EFL-036 ... 16

9. Thick Surface Layer on a Sample from Batch EFL-031 ......... 18

10. Surface Layer on Fuel Pin VC-1-2 ...................... 19

11. Typical As-Cast Microstructure of Batch EFL-029 ...........20

12. Typical Microstructure of Fuel Pin VC-1-2 .............21

13. Typical As-Cast Microstructure of Batch EFL-036 ..........22

14. Typical X-ray Spectra from the Globular Phase and Matrix of the Ternary Fuel; Near the Centerline of a Pin from Batch EFL -029

15. SEM EDX for the Surface Layer on a Sample from Batch EFL-029

16. SAM Data for the Surface Layer on a Bottom Sample from Batch EFL-029 


\section{LIST OF FIGURES}

No.

Title

Page

17. SAM Data for Inclusions in a Bottom Sample from Batch EFL 029 ........................................ 28

18. SAM Data for Inclusions in a Bottom Sample from Pin

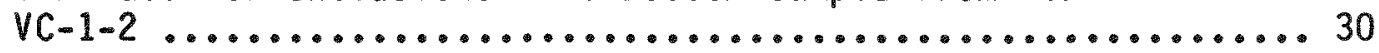

\section{LIST OF TABLES}

No. Title Page

1. Chemical Analysis of Pin, VC-1-2, Batch R450 ............ 4

2. Chemical Analyses of Current Casting Batches ............. 4

3. Results of Quantitative Metallography to Determine the Areal $\%$ of the Gobular Phase .......................... 11 
METALLOGRAPHIC CHARACTERIZATION OF UNIRRADIATED U-PU-Zr FUEL

by

R. V. Strain and J. E. Sanecki

ABSTRACT

A microstructural and micro-chemical characterization was performed on samples of $U-P u-Z r$ metal fuel from three recent casting batches and from a fuel pin that was fabricated in the 1960 's. The purpose of the characterization was to determine if features were present in the new castings that might indicate the irradiation performance of the newly fabricated pins could be expected to be different than the "old" fuel. Most of the effort was directed at samples from as-cast pins, but samples from bonded pins and segments of pins that had been heat-treated for $300 \mathrm{~h}$ at $750^{\circ} \mathrm{C}$ were also examined. The examinations revealed that a globular second phase was present in all of the fuel pins. Quantitative metallography indicated that the area fraction of this second phase ranged from about 0.02 to 0.055 and that the bonding operation or heat-treatment did not change the amount of the phase that was present. Scanning Auger spectroscopy indicated that this phase consisted of zirconium with several wt.\% of oxygen, carbon, and nitrogen present. A surface layer that also was high in zirconium was present on all of the samples. This layer tended to be thicker on samples from the bottom of the castings (10 to 50 microns) and thinner at the top (2 to 10 microns). The examinations found no significant differences between the current castings and the "old" fuel pins. 


\section{INTRODUCTION}

The irradiation performance of $\mathrm{U}-\mathrm{Pu}-\mathrm{Zr}$ fuel system was studied in the 1ate 1960's and the results of tests irradiated to a burnup of about 4.5 at. $\%$ indicated no problems under those irradiation conditions(1). The general method of fabricating the fuel pins for the current irradiation tests and those performed in the 1960's are similar. The pins are cast by melting the alloy in a crucible under a vacuum, plunging silica molds into the melt, and pressurizing the furnace to drive the melt up into the molds. This process of "injection casting" is described more completely in reference (2). Although the general technique of injection casting has not changed, some of the details of the process such as the techniques used to assure a homogenous composition in the melt have been altered in the current casting process.

This report describes the metallographic characterization of samples of fuel pins from three casting batches that are representative of the current casting process and characterization of a pin representative of the fuel fabricated in the 1960's. The purpose of this work was to determine if there were any microstructural or micro-chemical features that indicate differences between the current pins and the old pin that could influence their irradiation performance.

The microstructure of samples of the fuel pins from these casting batches have been studied using optical metallography and scanning electron microscopy (SEM). The micro-chemistry of these 
samples was determined using energy dispersive $X$-ray spectroscopy (EDX) on the SEM and Auger electron spectroscopy on the scanning Auger microprobe (SAM). The results from micro-chemical analyses using these instruments have large uncertainties in the values for Pu. Future examinations are expected to eliminate this deficiency in the current data.

\section{SAMPLE DESCRIPTION}

The samples examined in this study were obtained from the upper and lower ends of a single fuel pin from each casting batch. Samples from casting batches EFL-029, EFL-031, and EFL-036 as well as samples from the "old" fuel pin VC-1-2 (casting batch $\mathrm{R} 450$ ) have been characterized in this study. The nominal composition of these batches were:
EFL -029
$\mathrm{U}-8 \% \mathrm{Pu}-10 \% \mathrm{Zr}$
$E F L-031$
$U-8 \% P u-10 \% Z r$
$E F L-036$
$U-19 \% \mathrm{Pu}-10 \% \mathrm{Zr}$
VC $-1-2$
$U-15 \% \mathrm{Pu}-11 \% \mathrm{Zr}$ 
In addition to examining samples of pins in the as-cast condition some samples were examined after fuel pin bonding (about $2 \mathrm{~h}$ at $500 \mathrm{C})$ and some after a heat treatment of $300 \mathrm{~h}$ at $750 \mathrm{C}$. Samples from batch EFL-029 were examined after all three treatments (as-cast, bonded, and heat-treated), while samples from batch EFL-036 were examined in the as-cast and heat treated condition. Casting batch EFL-031 was examined in only the as-cast condition and the VC-1-2 pin was examined in the bonded condition only.

The actual chemical analysis for VC-1-2 (batch R450, including impurities is given in Table 1. Chemical analyses for the major constituents of the current batches are given in Table 2. Data on the impurity content of the current batches are unavailable at this time.

\section{GEMERAL FEATURES OF THE SAMPLES}

Samples were prepared for examination by cutting the pieces of the pins to provide samples that were about 0.2-in. long. The samples were placed in brass mounts using a low melting $\mathrm{Pb}-\mathrm{Bi}$ alloy so that transverse cross-section could be examined. The all-metal mounts were used to avoid problems in achieving the ultra-high vacuum required for the SAM. Resin mounts are too volatile to provide these high vacuums and clean surface conditions that are required for the SAM to be obtained. The samples were ground using SiC papers and polished using diamond pastes. The hot cell and glove boxes used in preparing and examining 
Table 1. Chamical Analys is of Archive Pin, vC-1-2, Batch R45

$\begin{array}{cl}\text { Element } & \text { Wt.\% } \\ \mathrm{Zr} & 11.2 \\ \mathrm{Pu} & 15.3 \\ \mathrm{U} & \text { Balance }\end{array}$

Impurities

ppm
500
490
3
150
200
50
50
100
50

Density, $g / c c$

15.3

Table 2. Chemical Analysis of Current Casting Batches

\begin{tabular}{|c|c|c|c|c|}
\hline Batch & $\begin{array}{l}\mathrm{Zr}, \\
\text { wt.\% }\end{array}$ & $\begin{array}{l}\mathrm{Pu}, \\
\mathrm{wt. \%}\end{array}$ & $\begin{array}{l}\text { U, } \\
\text { wt.\% }\end{array}$ & $\begin{array}{c}\text { Density } \\
\mathrm{g} / \mathrm{cc}\end{array}$ \\
\hline EFL-029 & 10.0 & 8.0 & 82.2 & 15.7 \\
\hline EFL-031 & 10.4 & 7.8 & 82.1 & 14.7 \\
\hline EFL-036 & 10.4 & 18.8 & 71.4 & 15.7 \\
\hline
\end{tabular}


these samples had nitrogen atmosphere with oxygen and moisture contents of about 100 and 500 ppm respectively. Even in this relatively good atmosphere the surface of these samples oxidized fairly rapidly. As a result, these samples were repolished using 1 micron diamond paste just prior (within 5 to 10 minutes) to placing them in the electron beam instruments.

Nearly all of the microstructural characterization of the samples was performed on the SEM. Optical microscopy of samples in the as-polished condition revealed very little structure. A glabular phase was discernible, but was difficult to photograph as it appeared to be in relief, slightly above the surface of the matrix. The samples were not etched to bring out the microstructure for optical microscopy for several reasons. The etching process might interfere with the micro-chemical analyses that were to be performed on the samples. Initial attempts to etch the samples were unsuccessful in producing observable microstructures (probably because no structure existed in the samples tried). And finally, the SEM was capable of revealing the microstructures without etching the samples, so there was no real need for the optical microscopy.

\section{A. Globular Phase Distribution}

The SEM examinations showed two prominent features in the aspolished samples. The first feature was that castings contained small amounts of porosity that were assumed to be shrinkage voids or bubbles in the castings. An example of voids that may be 
shrinkage voids because of their relatively small size and their apparent formation along grain boundaries is shown in the micrograph on the left side of Figure 1. An example of a larger, round void that has been categorized as a gas bubble because of its spherical shape is shown in the micrograph on the right side of Figure 1. Casting defects of these types were found in nearly all of the cross-sections that were examined during this study. The casting defects generally represented an extremely small area fraction of the samples, but no effort to quantify them was made as the amount of porosity in the castings is probably more accurately reflected in its density.

The other prominent feature in these cross-sections was the presence of a globular second phase. Typical examples of this globular phase are shown in Figures 2 and 3 . The distribution of the globular phase is shown in the diametral strips across some of the samples that are shown in Fig. 4. These micrographs were intentionally made with high contrast so that the volume percent occupied by the globular phase could be determined using a Quantimet image analyzer. The globular phase is randomly distributed in the samples with some areas having relatively high concentrations of the phase and other areas being relatively devoid of it. Results of the determination of the volume fraction of the globular phase are given in Table 3 . The values reported in this table include small voids in the castings in addition to the globular phase. Including these voids in the 


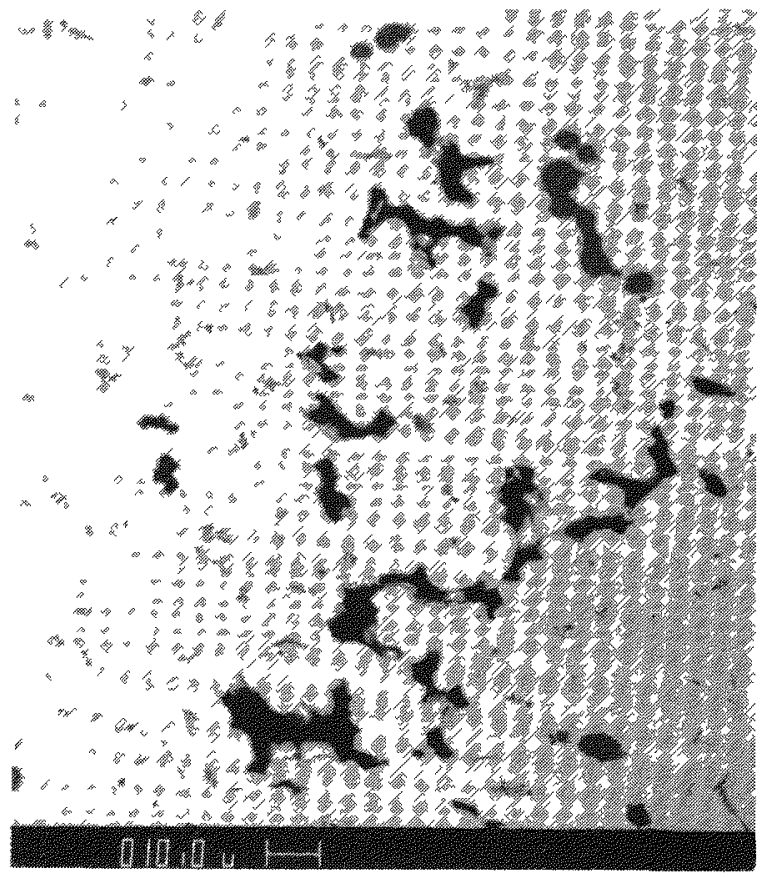

SHRINKAGE VOIDS

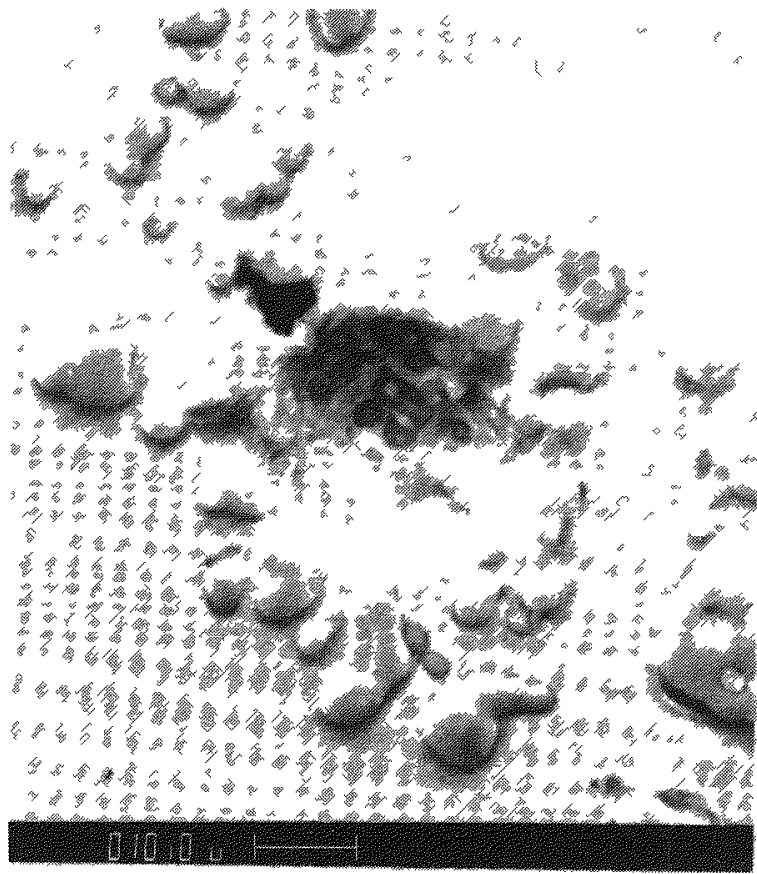

GAS BUBBLE

Fig. 1. Typical Casting Defects in the Current U-Pu-Zr Fuel Pin 


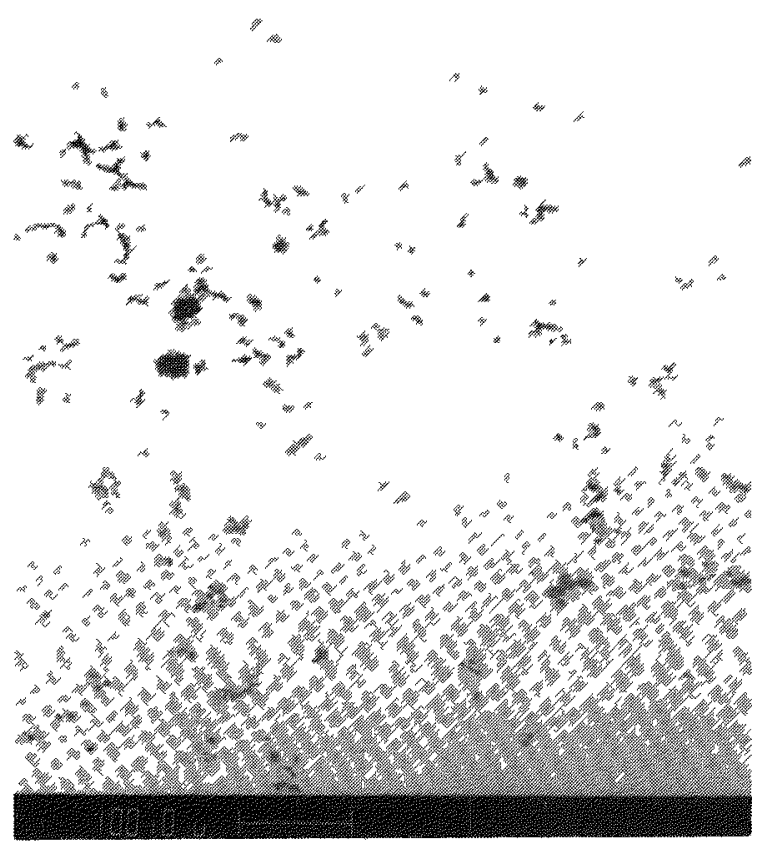

B.S.E. IMAGE, 100X

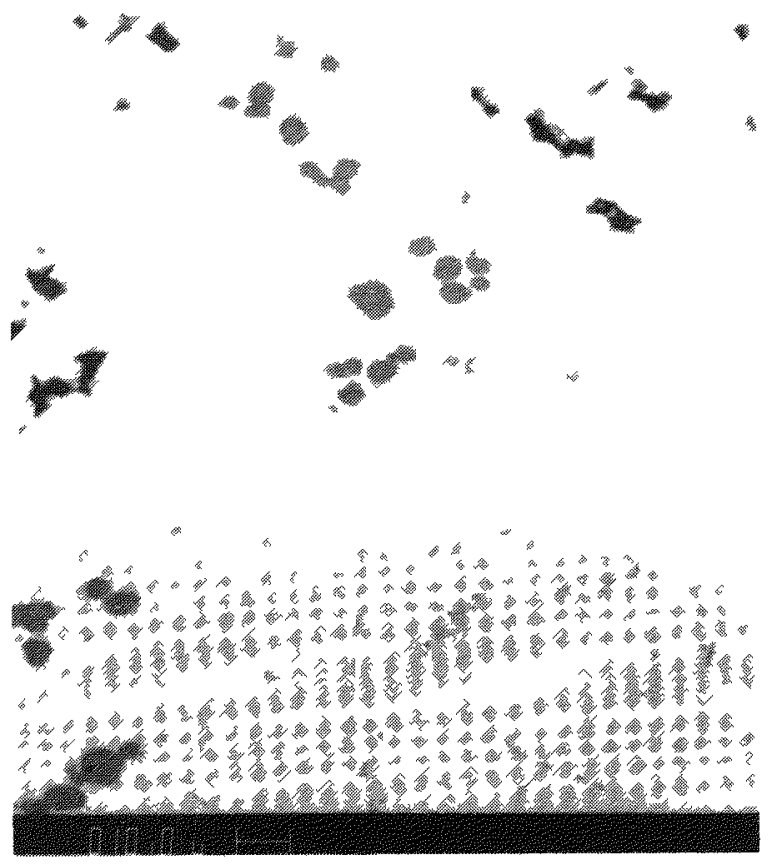

B.S.E. IMAGE 500X

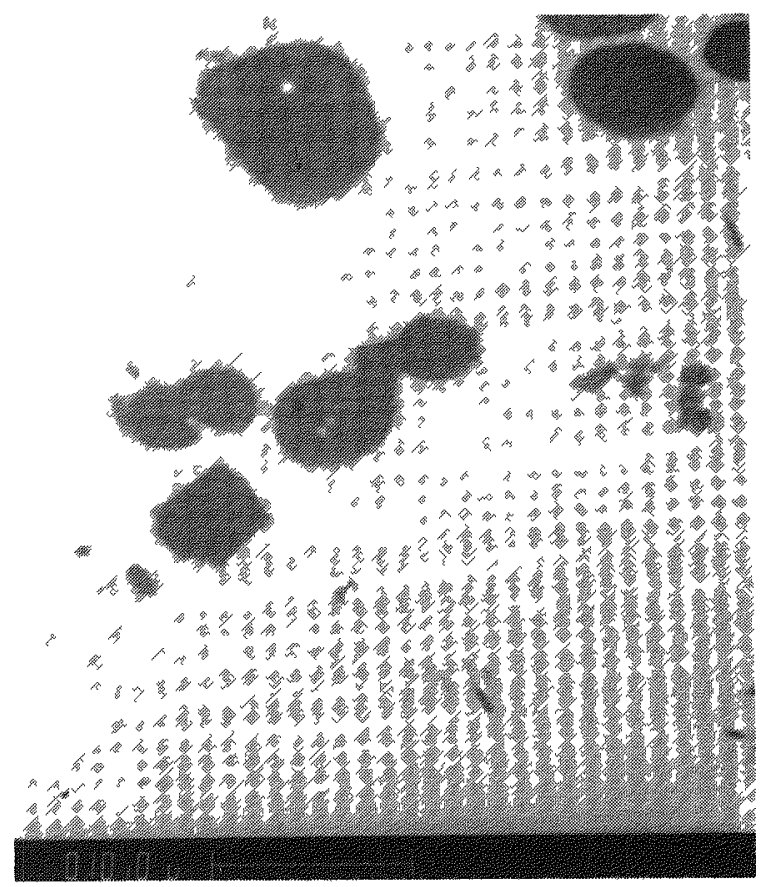

B.S.E. IMAGE, 2000X

Fig. 2. Typical Examples of the Globular Phase: Top of the Pin from Casting Batch EFL-029 


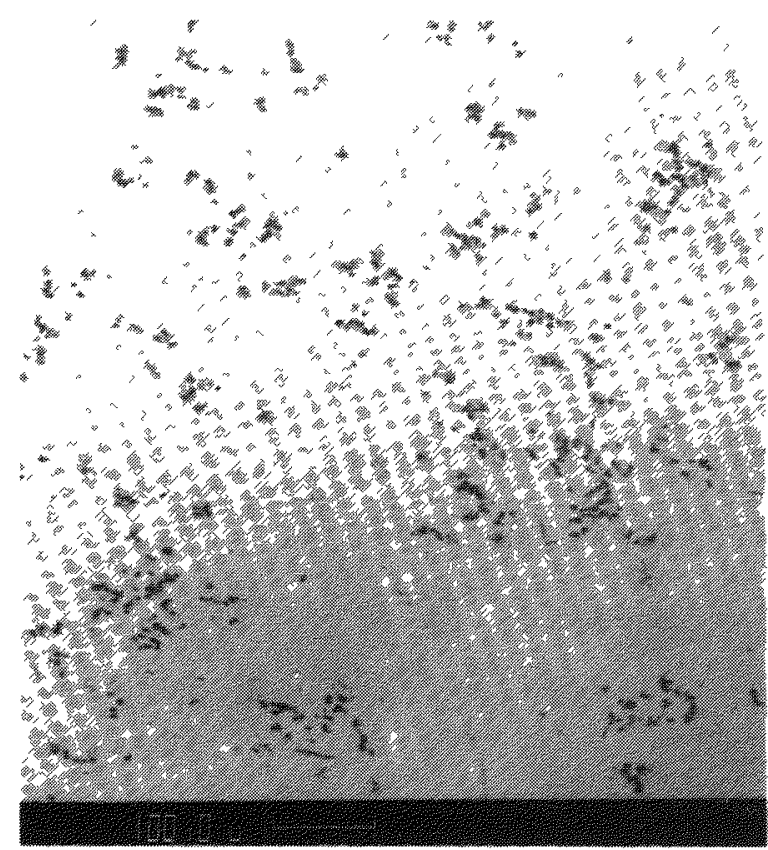

B.S.E. IMAGE, 100X



B.S.E. IMAGE 500X

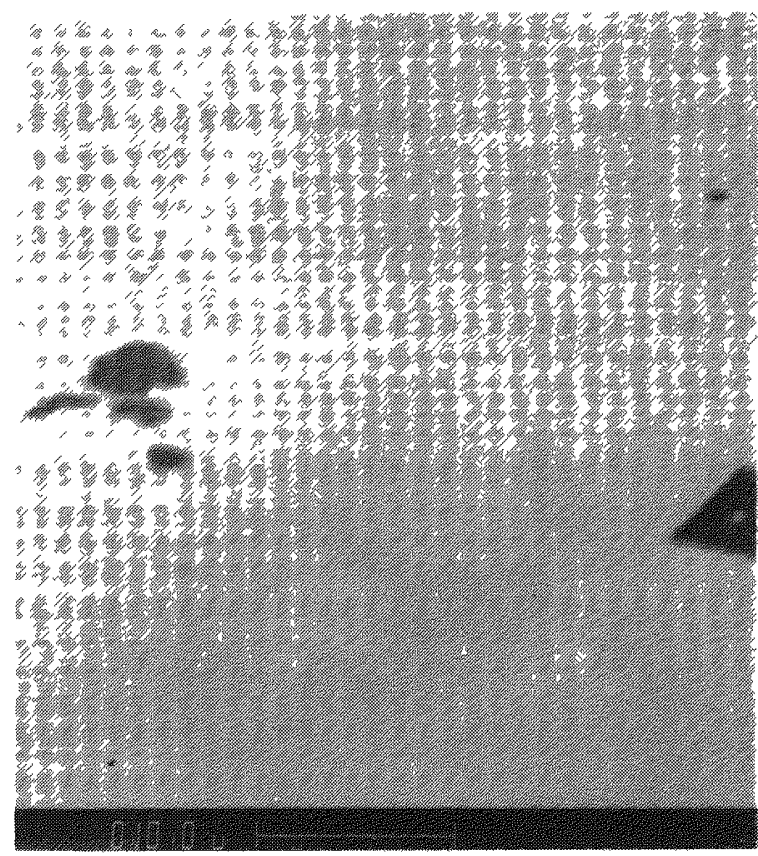

B.S.E. IMAGE, 2000X

Fig. 3. Typical Examples of the Globular Phase: Bottom of the Pin from Casting Batch EFL-029 


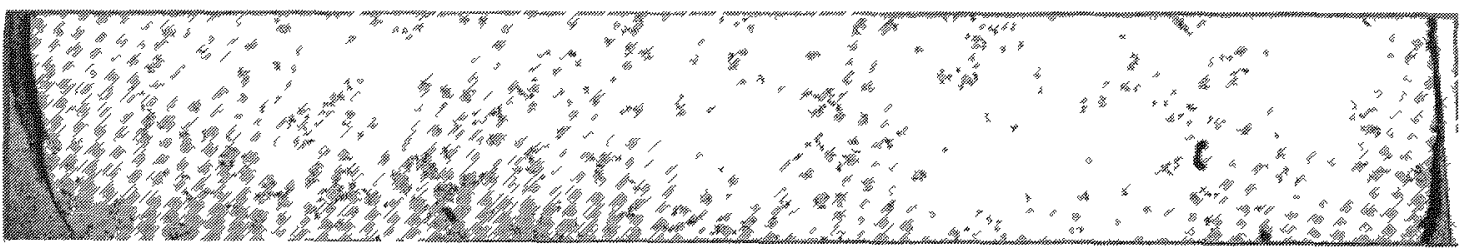

EFL-029: AS-CAST

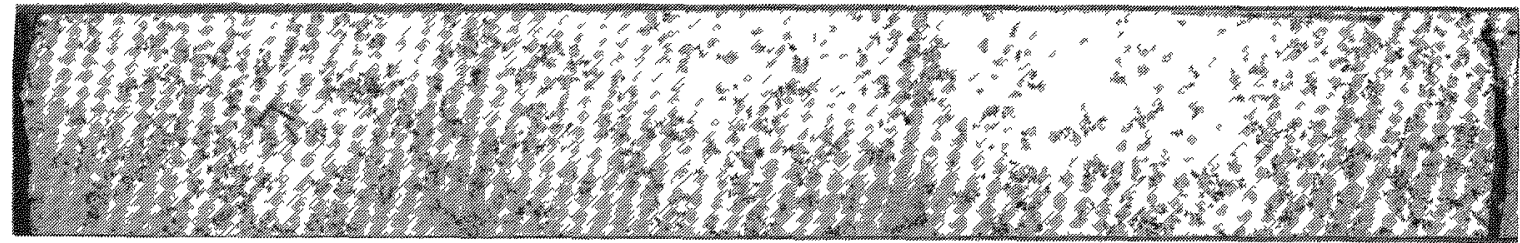

EFL-031: AS-CAST

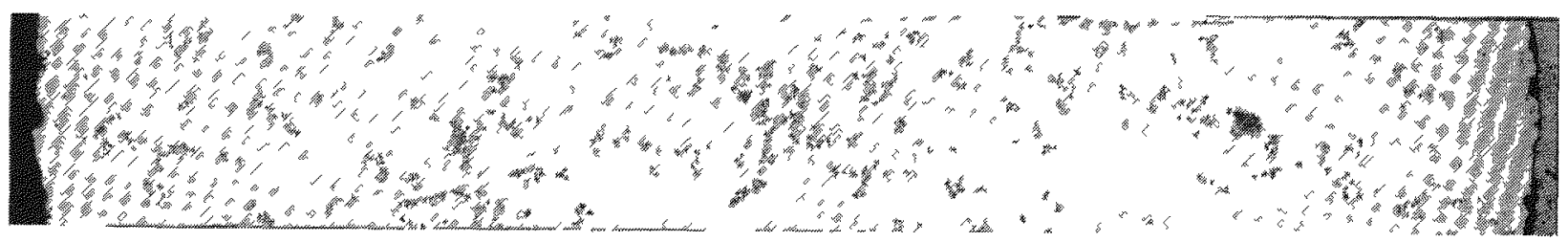

EFL-036: AS-CAST

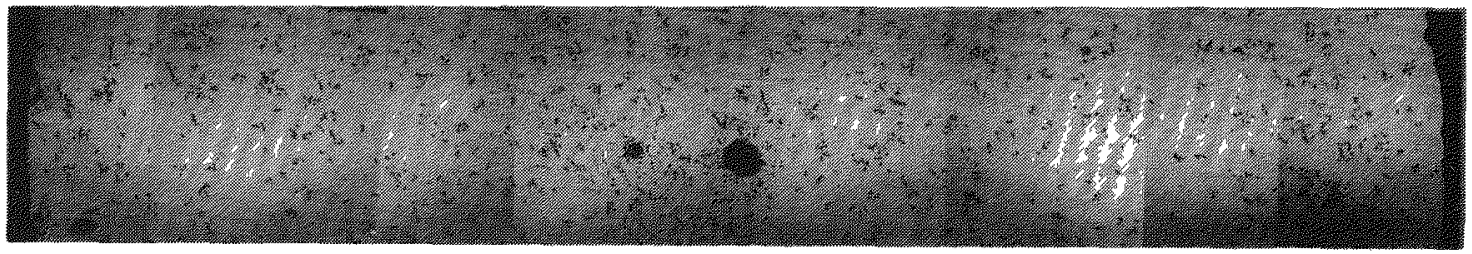

EFL-029· BONDED

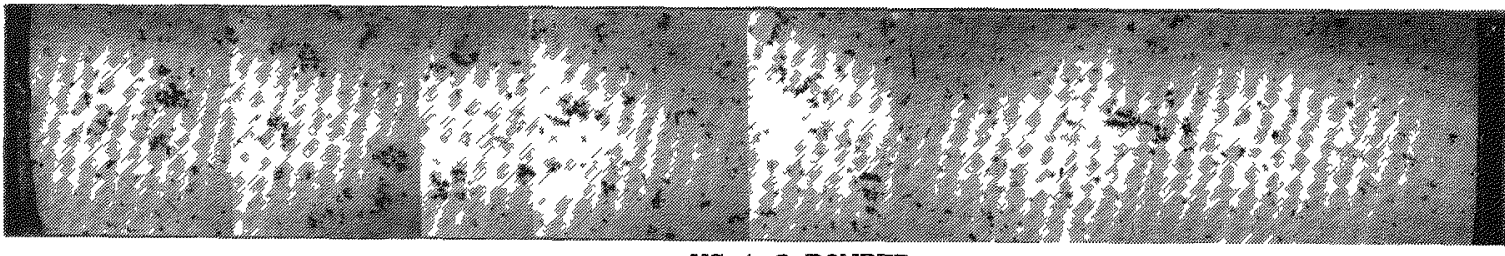

VC-1-2: BONDED

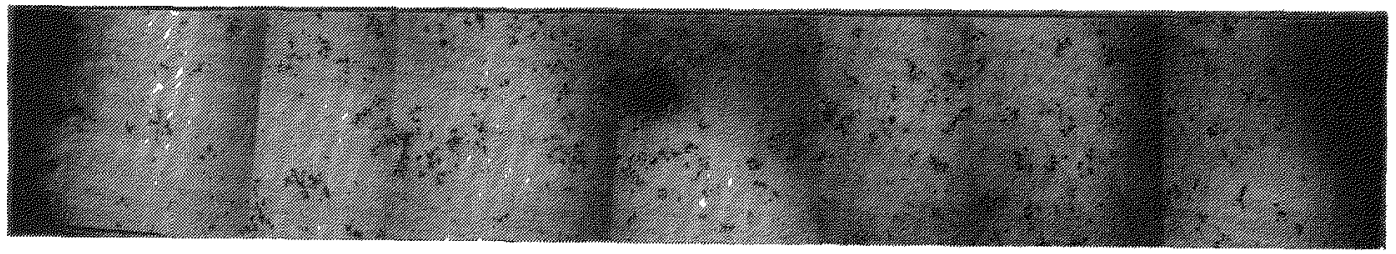

EFL-029: HEAT TREATED

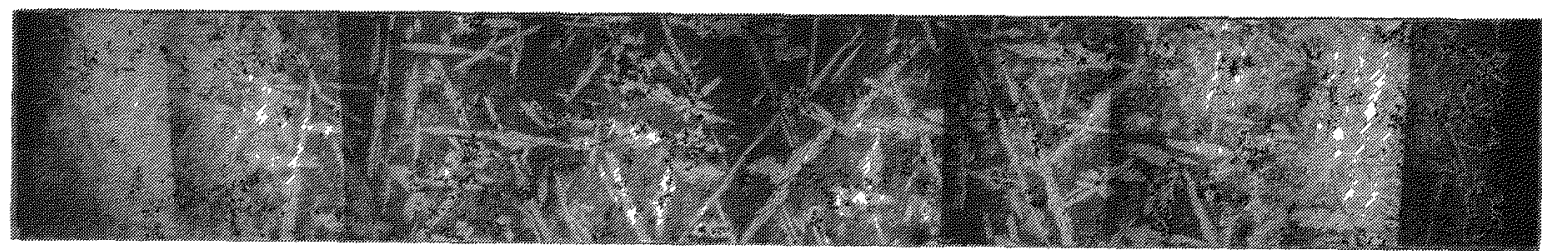

EFL-036: HEAT TREATED

Fig. 4. Strips Across Selected Samples at Approximately 30x 
Table 3. Results of Quantitative Metallography to

Determine the Areal \% of the Globular Phase

\begin{tabular}{|c|c|c|c|c|c|c|c|c|c|c|c|}
\hline $\begin{array}{c}\text { Sample } \\
\text { No. } \\
\end{array}$ & $\begin{array}{c}\text { Casting } \\
\text { Batch }\end{array}$ & Location & A & $\underline{B}$ & $\underline{C}$ & $\underline{D}$ & $\underline{\mathbf{E}}$ & $\underline{F}$ & $\underline{G}$ & H & AVG \\
\hline $286 \mathrm{~B}-16$ & $V C-1-2$ & Bottom & 2.50 & 2.70 & 2.83 & 2.05 & 1.04 & .57 & 2.67 & 1.10 & 1.93 \\
\hline $290 B-3$ & $E F L-029$ & Bottom & 3.28 & 5.70 & 2.98 & 2.36 & 1.68 & 3.30 & 0.98 & & 2.90 \\
\hline $293 A-3$ & $E F L-036$ & Top & 2.64 & 5.23 & 2.38 & .70 & .77 & & & & 2.34 \\
\hline $295 A-2$ & EFL-031 & Bottom & 2.65 & 7.12 & 9.11 & 5.77 & 4.82 & 4.51 & & & 5.66 \\
\hline $295 A-3$ & $E F L-031$ & Bottom & 7.11 & 5.27 & 2.82 & 4.71 & 3.95 & 4.72 & 9.71 & & 5.47 \\
\hline $309 A-1$ & EFL-029 & Bonded & 3.57 & 3.74 & 1.72 & 1.25 & 1.68 & .43 & 1.49 & & 1.98 \\
\hline $309 A-2$ & $E F L-029$ & Bonded & 3.48 & 1.54 & 2.67 & 2.48 & 3.51 & 3.50 & 1.47 & 1.95 & 2.58 \\
\hline
\end{tabular}


globular phase tends to over estimate the volume fraction of the phase. However, the large voids were not included and the instrument was not capable of detecting the smaller inclusions so the error may have actually been on the low side rather than the high side of these values. Estimates based on manual point counting to determine the amount of the globular phase were about twice those obtained from the Quantimet. The Quantimet measurements showed that all of these samples except those from batch EFL-031 contained between 1.5 and 3.4 volume \% of the globular phase. Both of the samples from EFL-031 that were examined contained higher amounts (about 5.5 volume \%) of the globular phase. These data also indicate that there is no tendency for the amount of the globular phase to increase during bonding or $300 \mathrm{~h}$ heat treatment at $750 \mathrm{C}$.

\section{B. Surface Layers}

Initial SEM examination of the samples from batch EFL-029 revealed that this casting has a layer on its outer surface. This layer was thicker on the sample from the bottom of the fuel pin than it was on the sample from the top of the fuel pin as shown in Figs. 5 and 6 . The examination of additional samples of the U-Pu-Zr fuel confirmed this initial finding. Typical areas of the surface layer are shown in Figs. 7 and 8 . These results indicate that the layers were thicker on the samples from the bottom of the fuel pins (varied from 10 to 50 microns) and thin- 


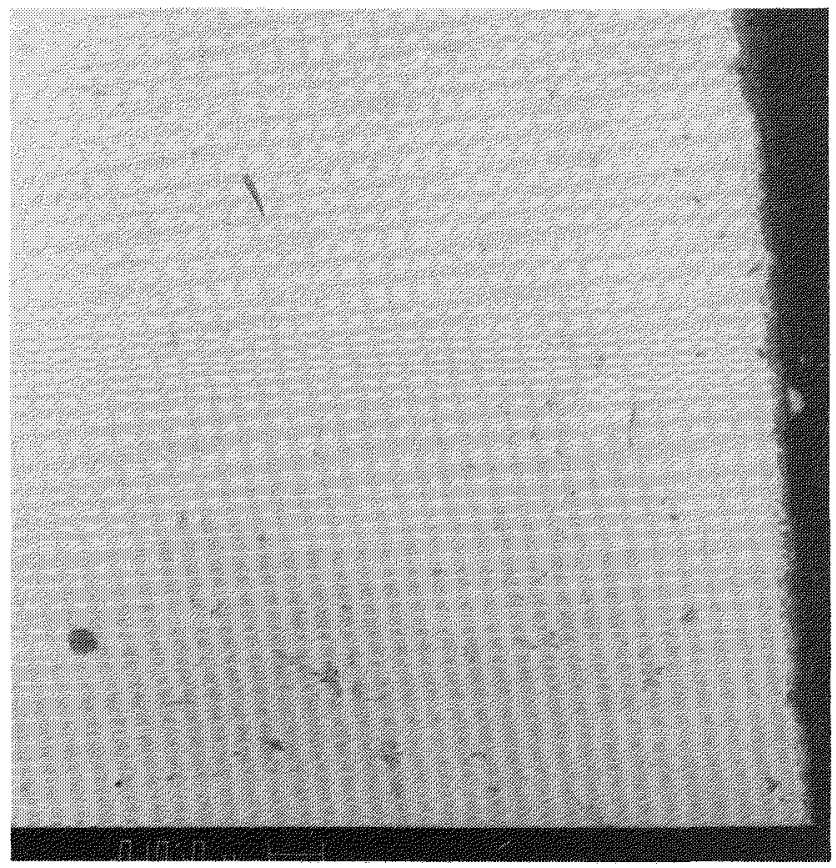

S.E. IMAGE, 500X

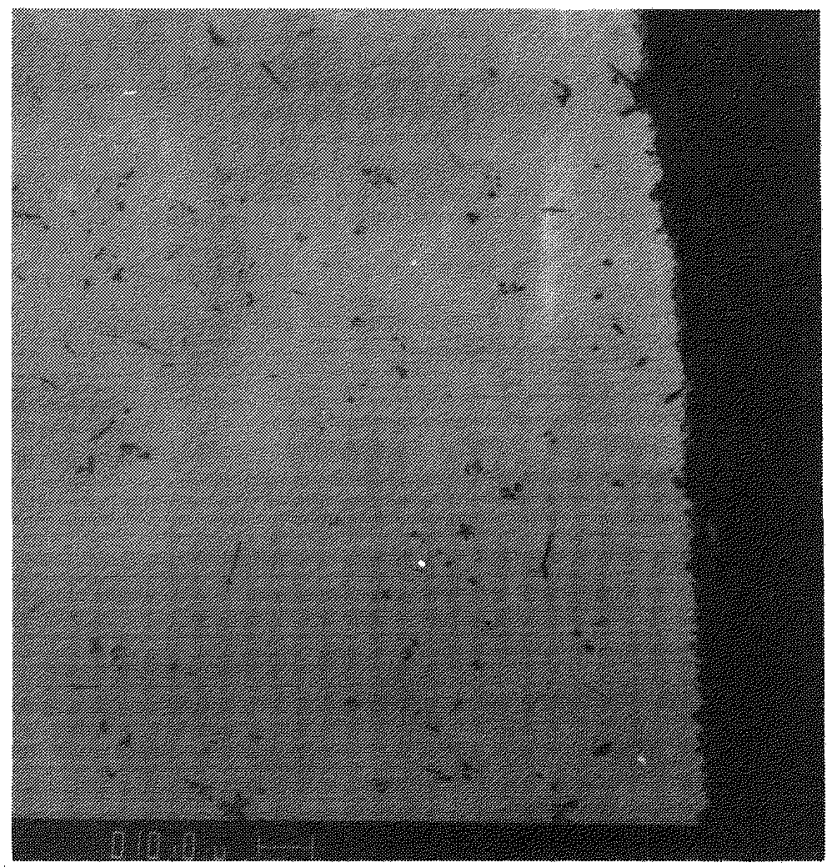

B.S.E. IMAGE 500X



\section{B.S.E. IMAGE, 2000X}

Fig. 5. Microstructure of the Fuel Near the Edge of the Sample and the Layer on the Surface Near the Top of the Pin

from Batch EFL-029 


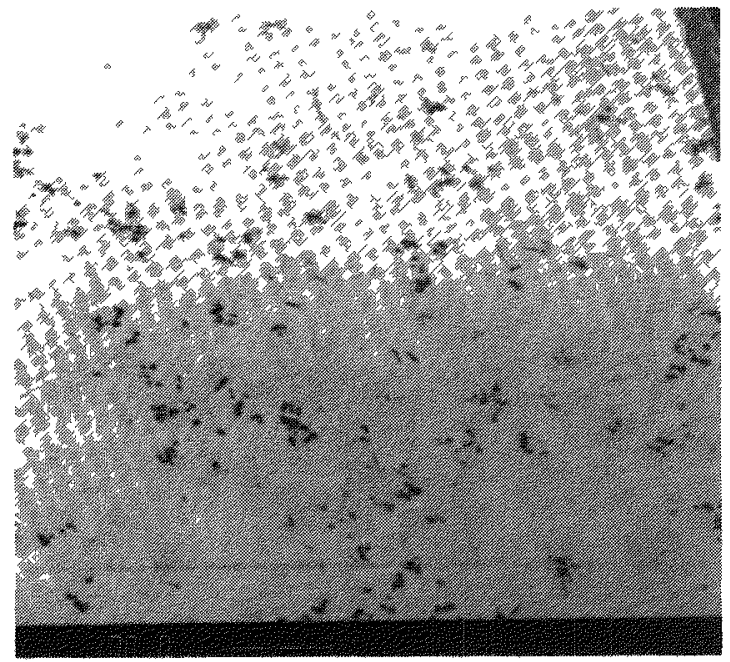

B.S.E. IMAGE, 100X

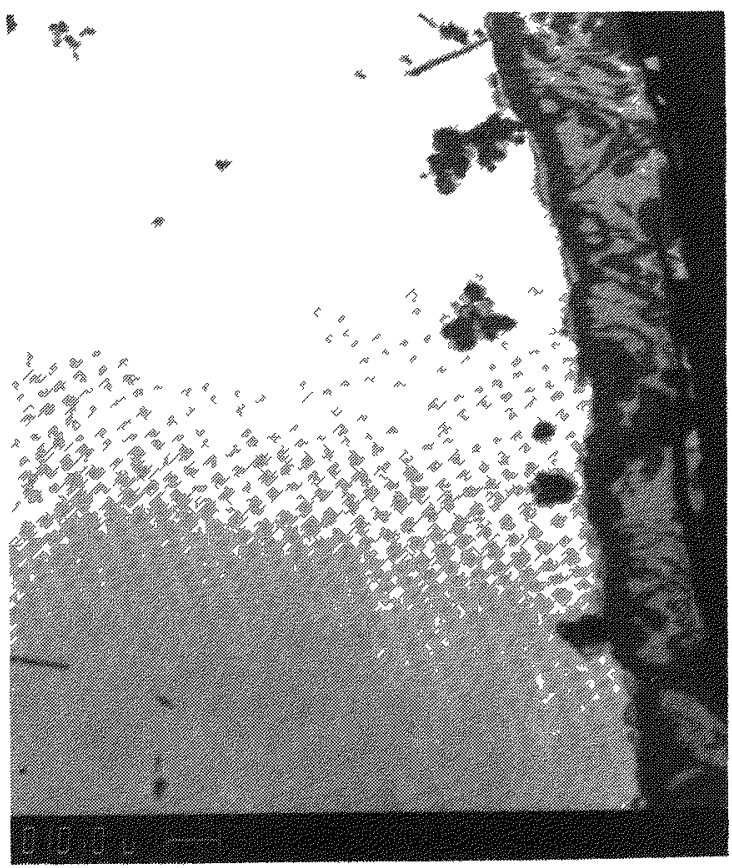

B.S.E. IMAGE 500X

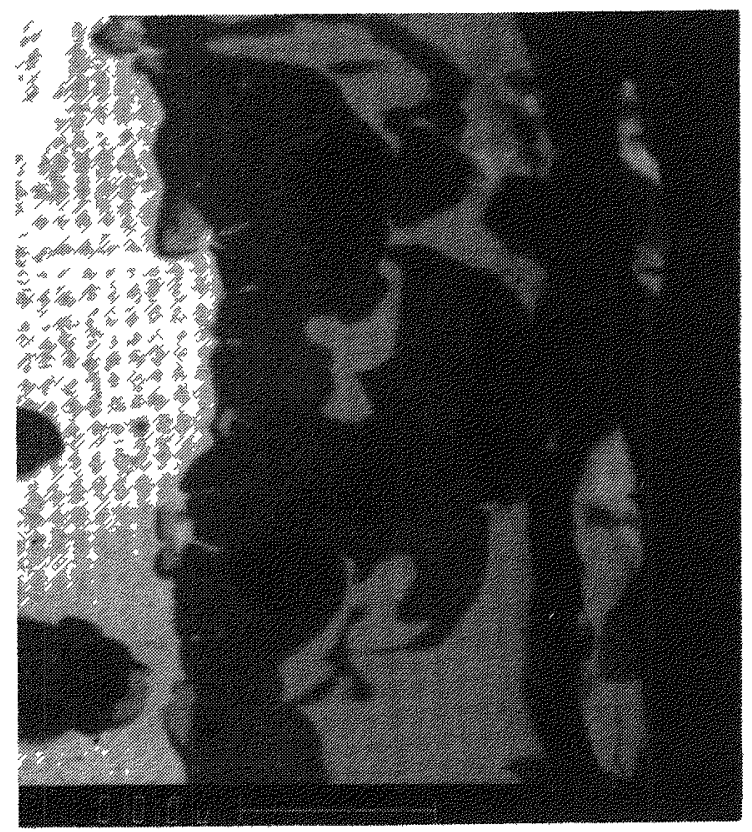

B.S.E. IMAGE, $2000 \mathrm{X}$

Fig. 6. Microstructure of the Fuel Near the Edge of the Sample and the Layer on the Surface Near the Bottom of the Pin from Batch EFL-029 

是
縤
是
䍃

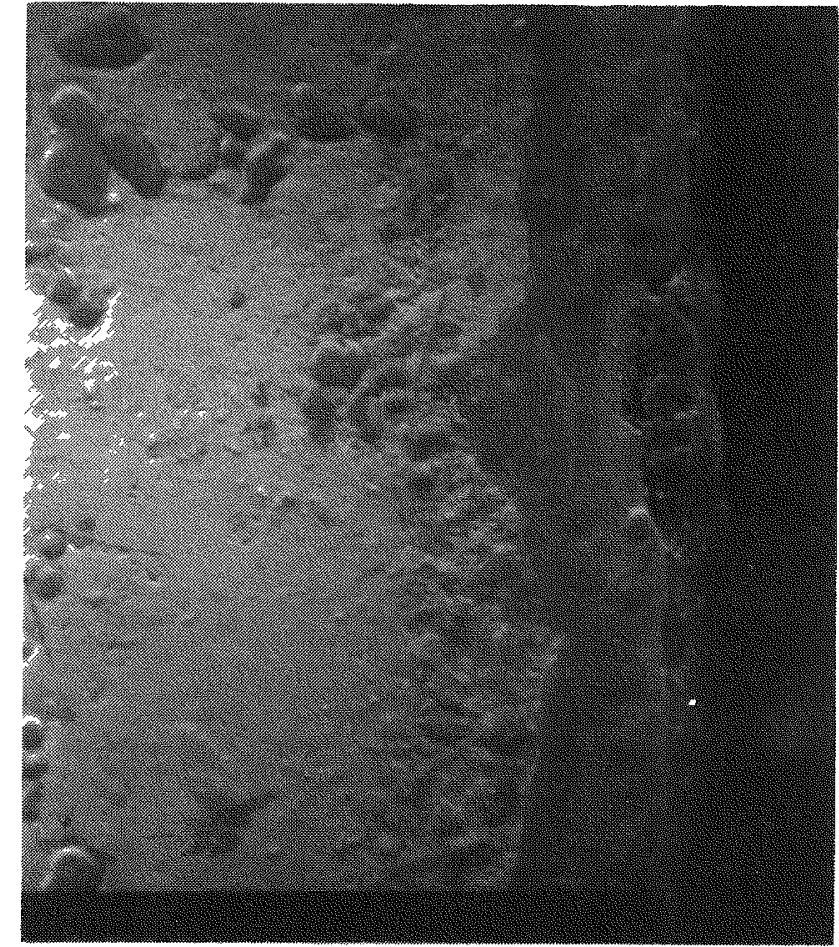

S.E. IMAGE, 500X

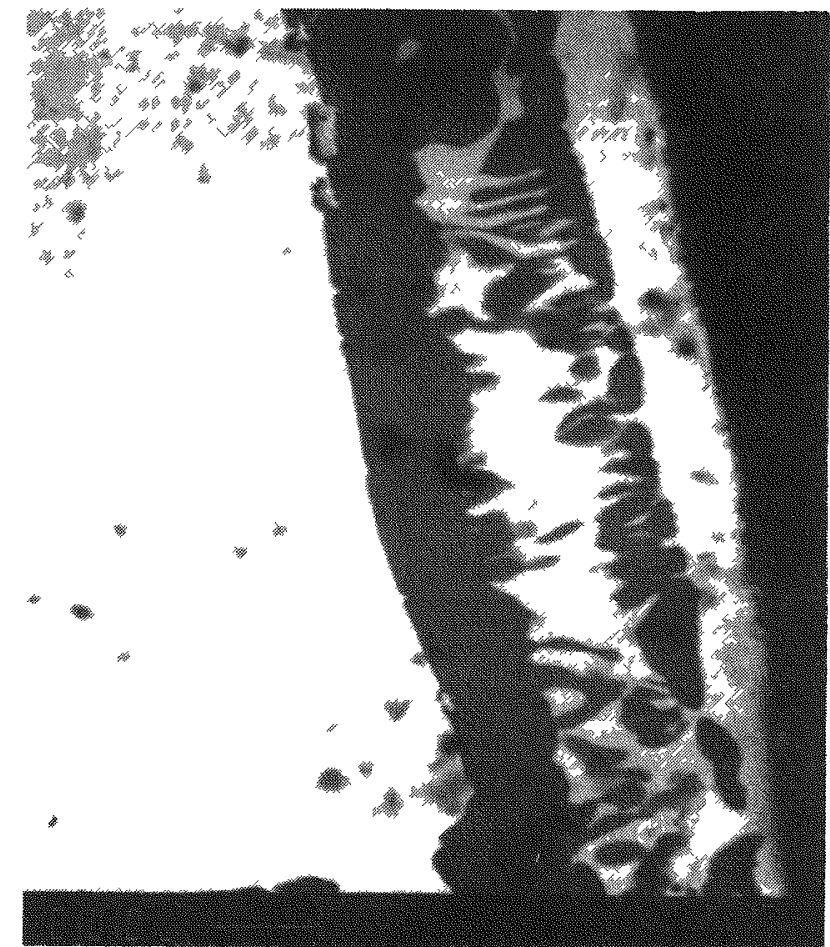

B.S.E. IMAGE, 1000X

Fig. 7. Surface Layer on Bottom Samples from Casting Batch EFL-031 


$$
\text { 獣 }
$$$$
\text { 是 }
$$



HIGH CONTRAST, 1000X
宦密

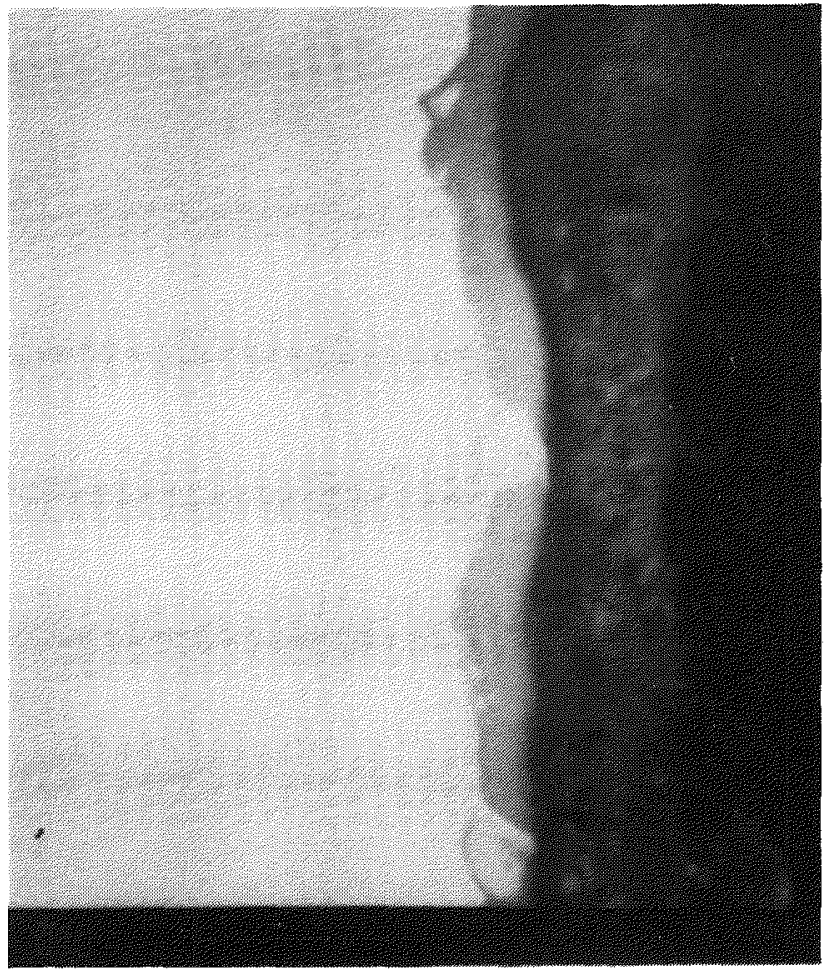

LOW CONTRAST, 2000X

Fig. 8. Surface Layer on Bottom Samples from Casting Batch EFL-036 
ner on samples from the top of the fuel pins (2 to 10 microns). At several locations on the perimeter of the bottom sample from EFL-031, a very thick (50 microns) layer was present as shown in Fig. 9. In some locations on some of the samples (EFL-029 bonded, EFL-031, and EFL-036), the surface material appeared to consist of a dense inner layer and a less dense outer layer. It may be that this less dense outer layer was missed during the initial examination of these samples. At high contrast in the BSE mode the less dense outer layer does not appear in the images as is indicated in Fig. 8. The outer layer is apparent only in the SE mode or at low contrast in the BSE mode. A thin intermittent surface layer was found on a sample from the VC-1-2 pin during a reexamination of this sample as shown in Fig. 10. This surface layer had been missed during early examinations of this pin.

\section{Grain Boundaries and Other Features}

Although few microstructural features were present in the matrix of the as-polished samples, some typical micrographs at a magnification of about 500X are shown in Figs. 11, 12, and 13. The micrographs of samples from EFL-029 and the VC-1-2 pin show that in addition to the globular phase, dendrites (leafy or flowery structures) and rod-shaped inclusions were present. Using very high contrast in the BSE mode, the grain boundaries in samples from the EFL-036 batch were apparent as shown in Fig. 13. Close examination of the SE images of the VC-1-2 pin also show faint traces of the grain boundaries. Efforts to bring out the 


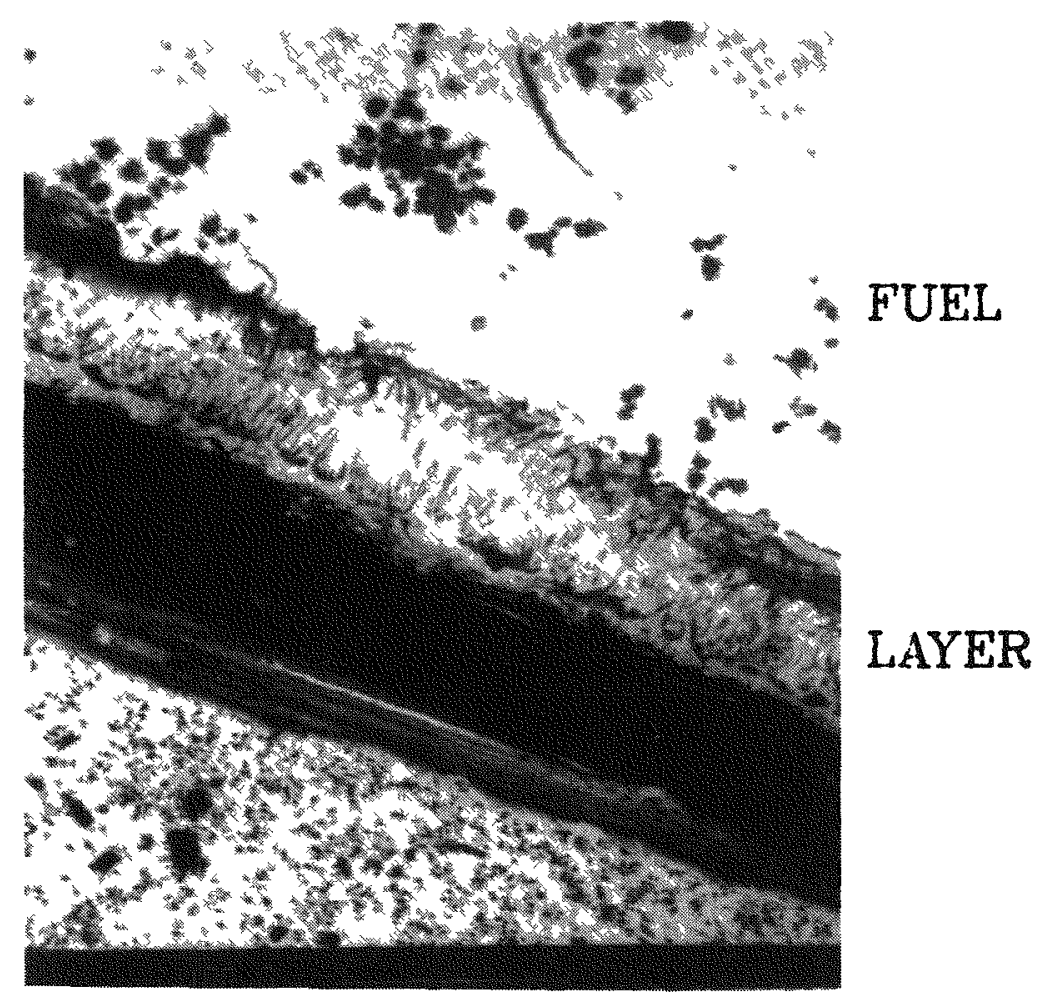

200X, B.S.E. IMAGE

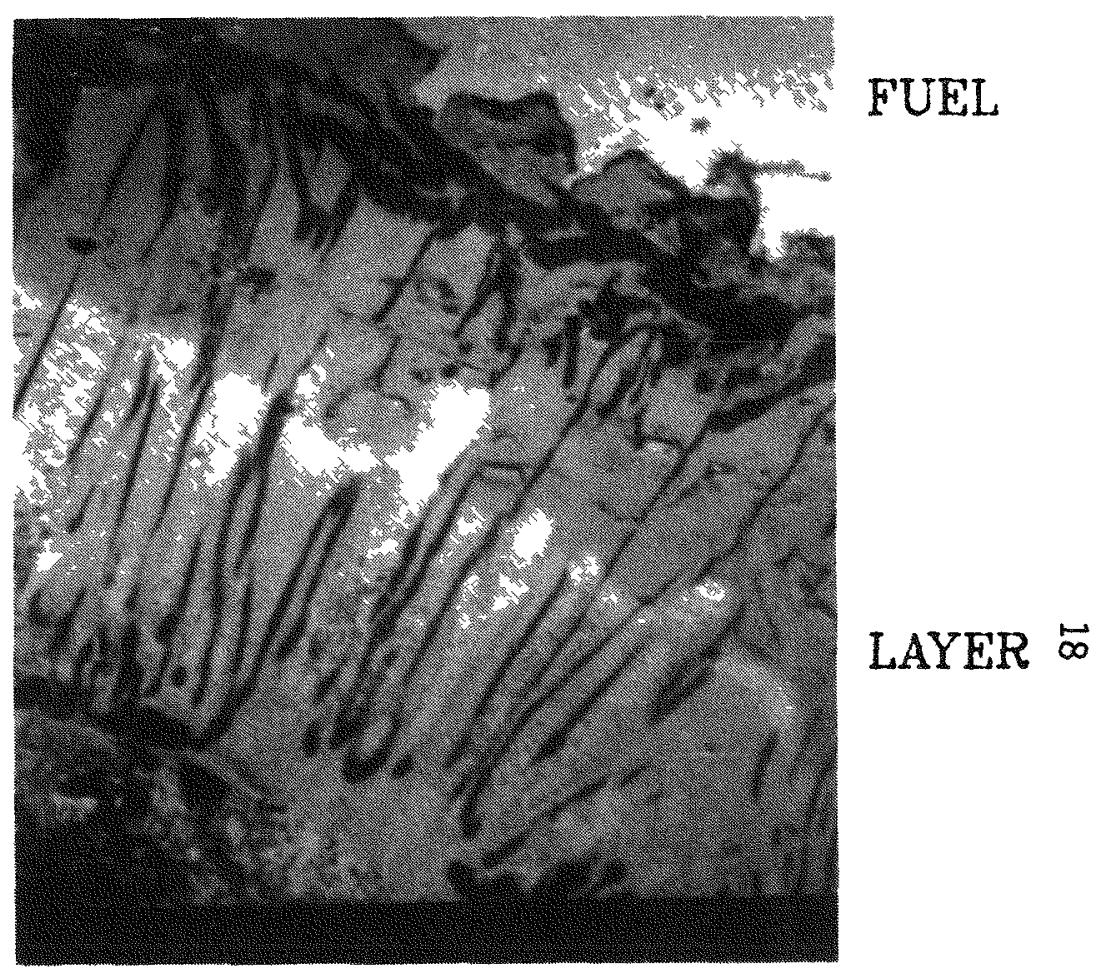

1000XM B.S.E. IMAGE

Fig. 9. Thick Surface Layer on a Sample from Batch EFL-031 


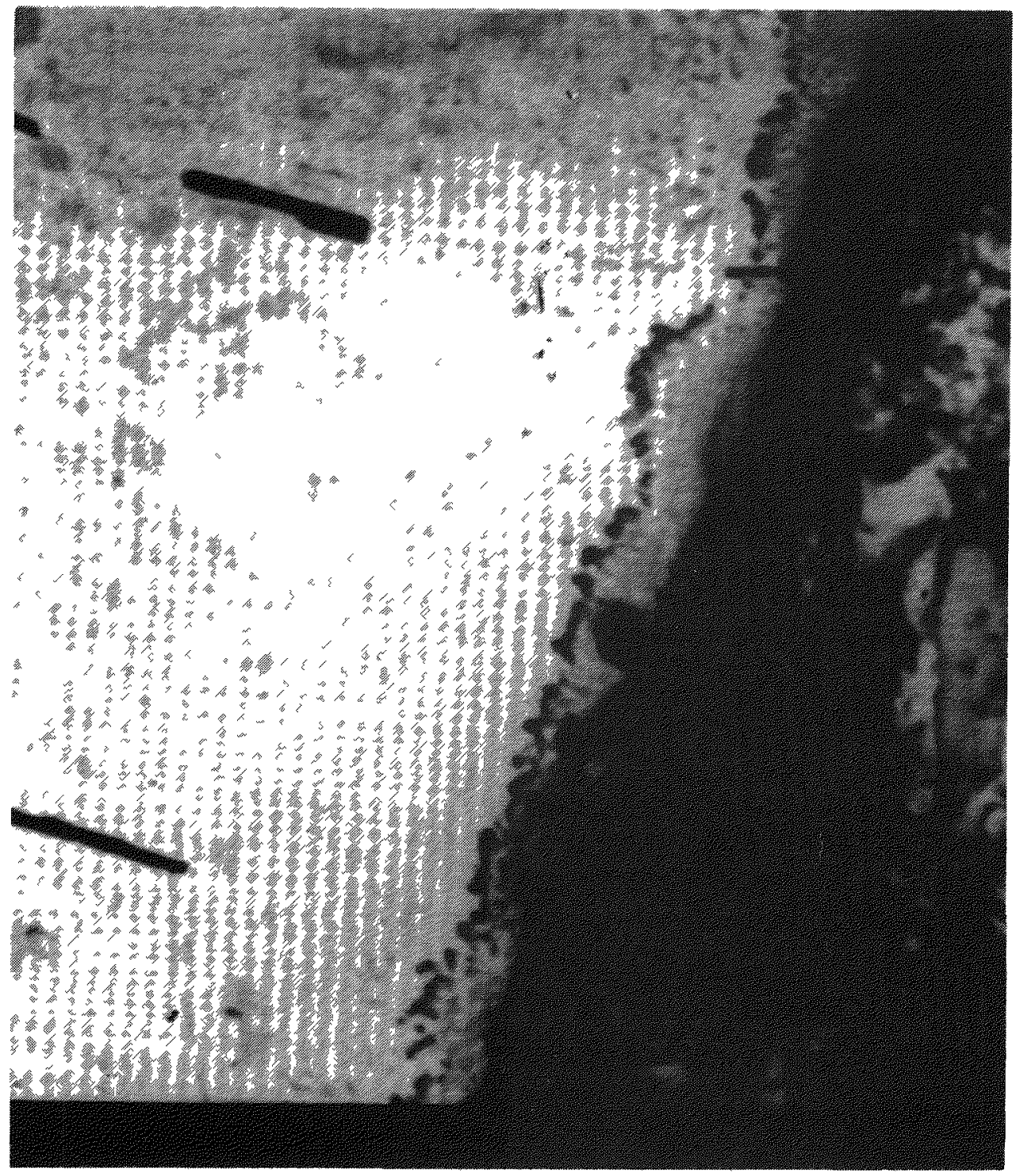

Fig. 10. Surface Layer on Fuel Pin VC-1-2 




BOTTOM SAMPLE

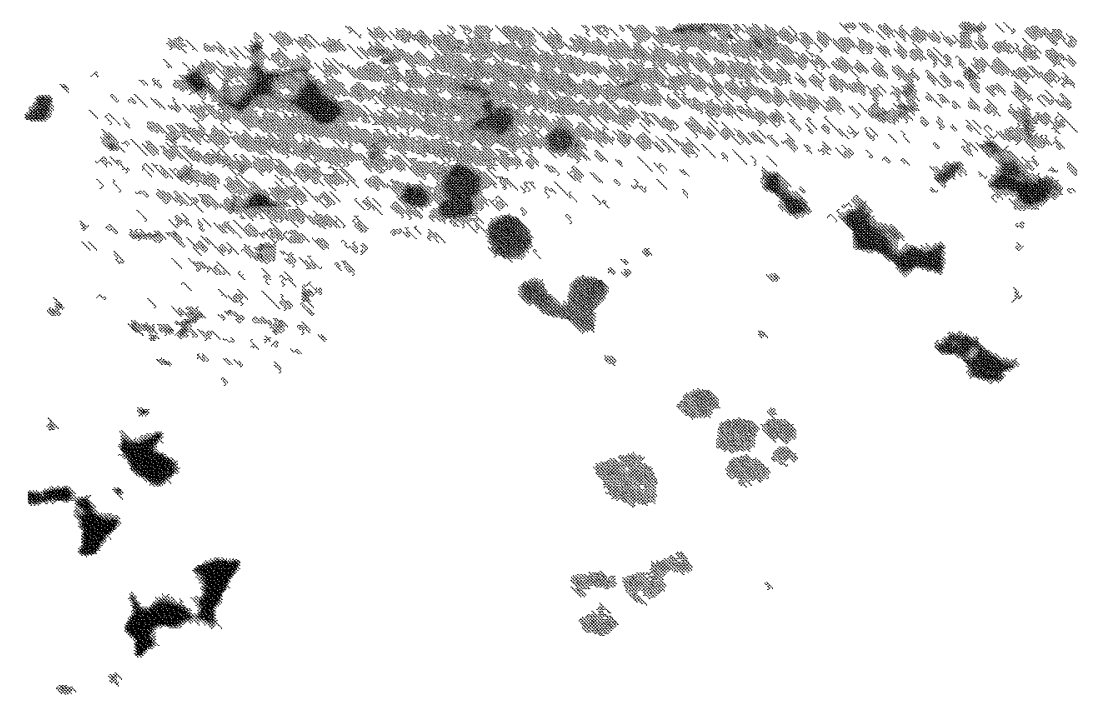

กั

Fig. 11. Typical As-Cast Microstructure of Batch EFL-029 




S.E. IMAGE, 500X

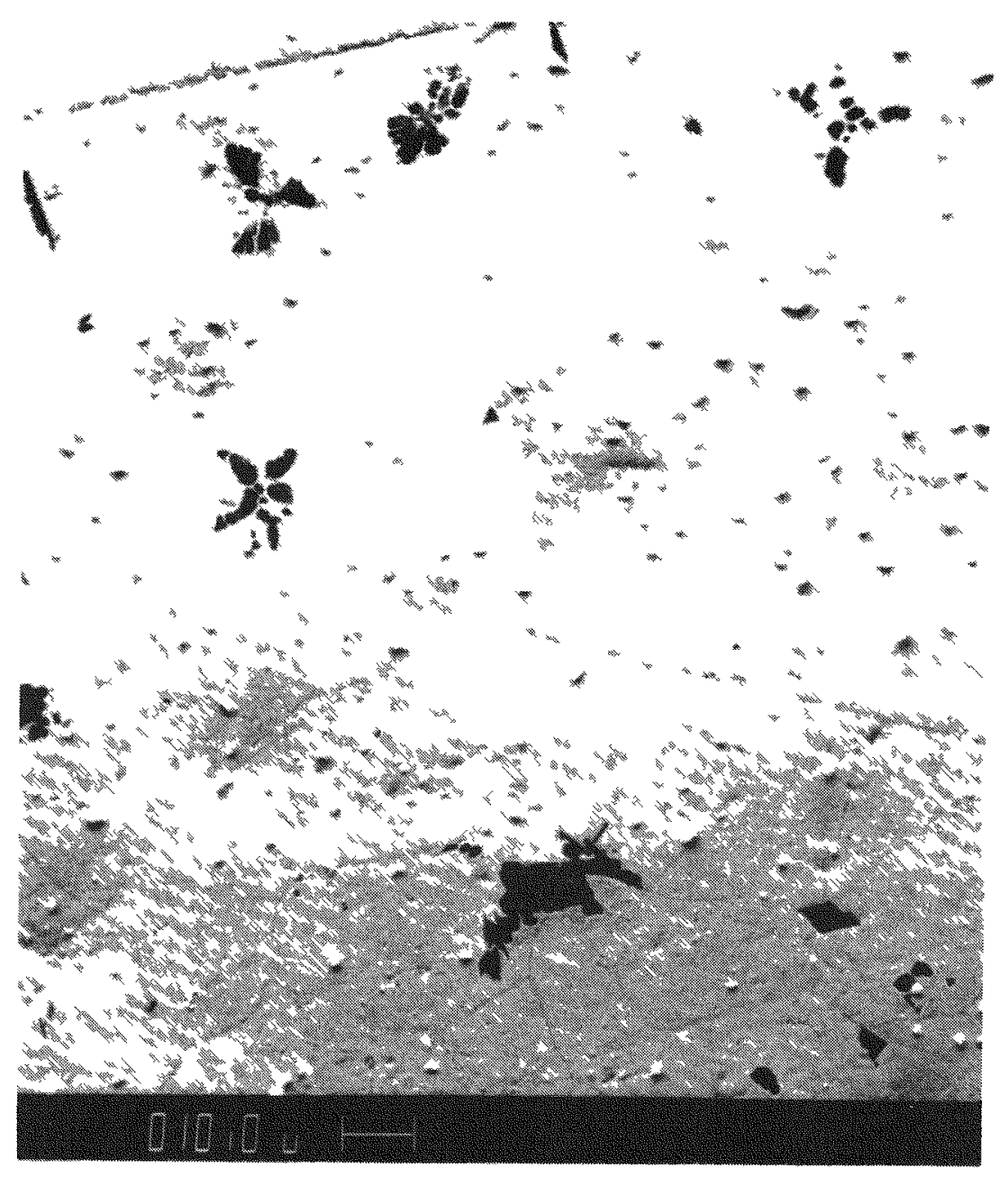

S.E. IMAGE, 500X

Fig. 12. Typical Microstructure of Fuel Pin VC-1-2 


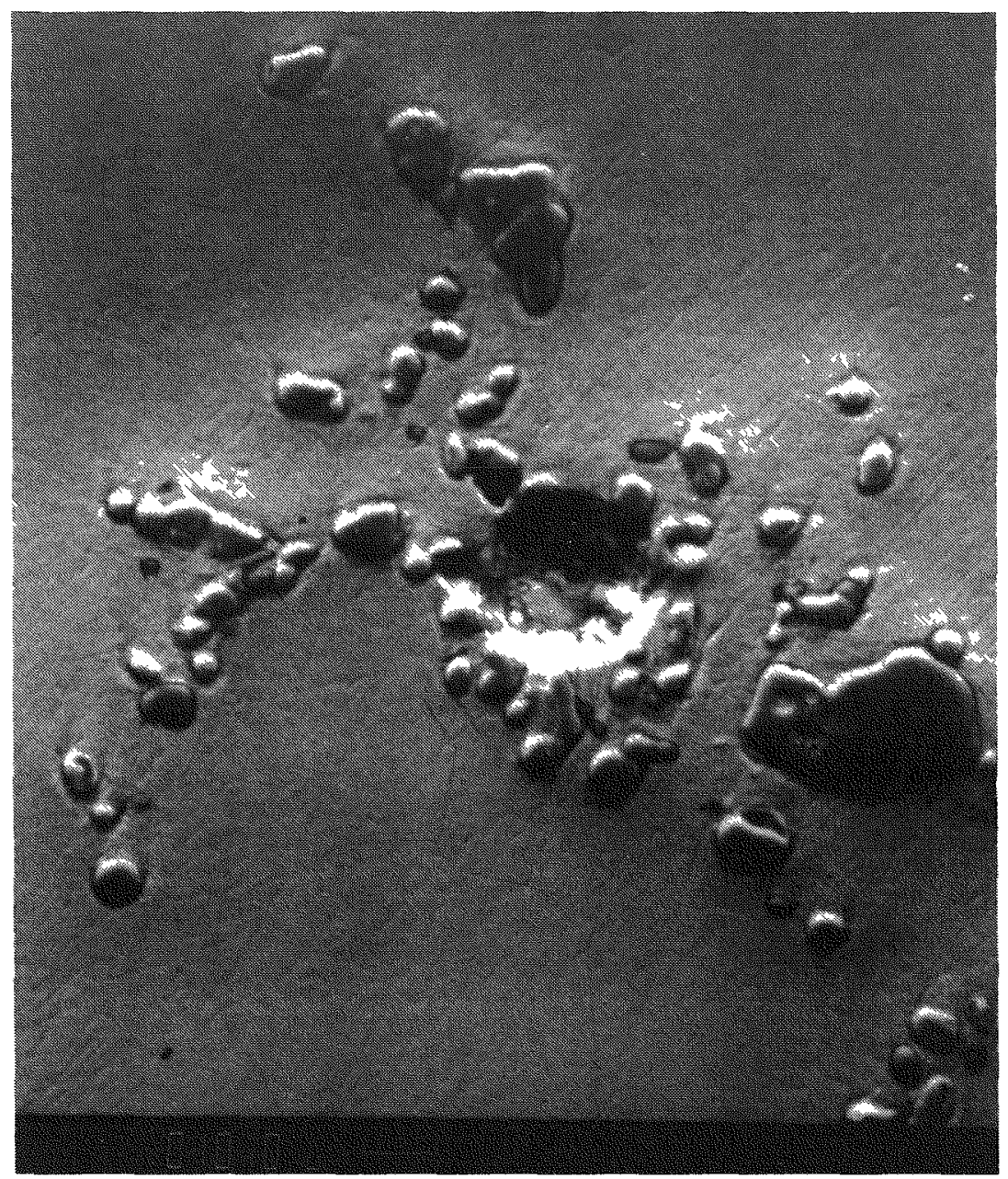

S.E. IMAGE, 500X

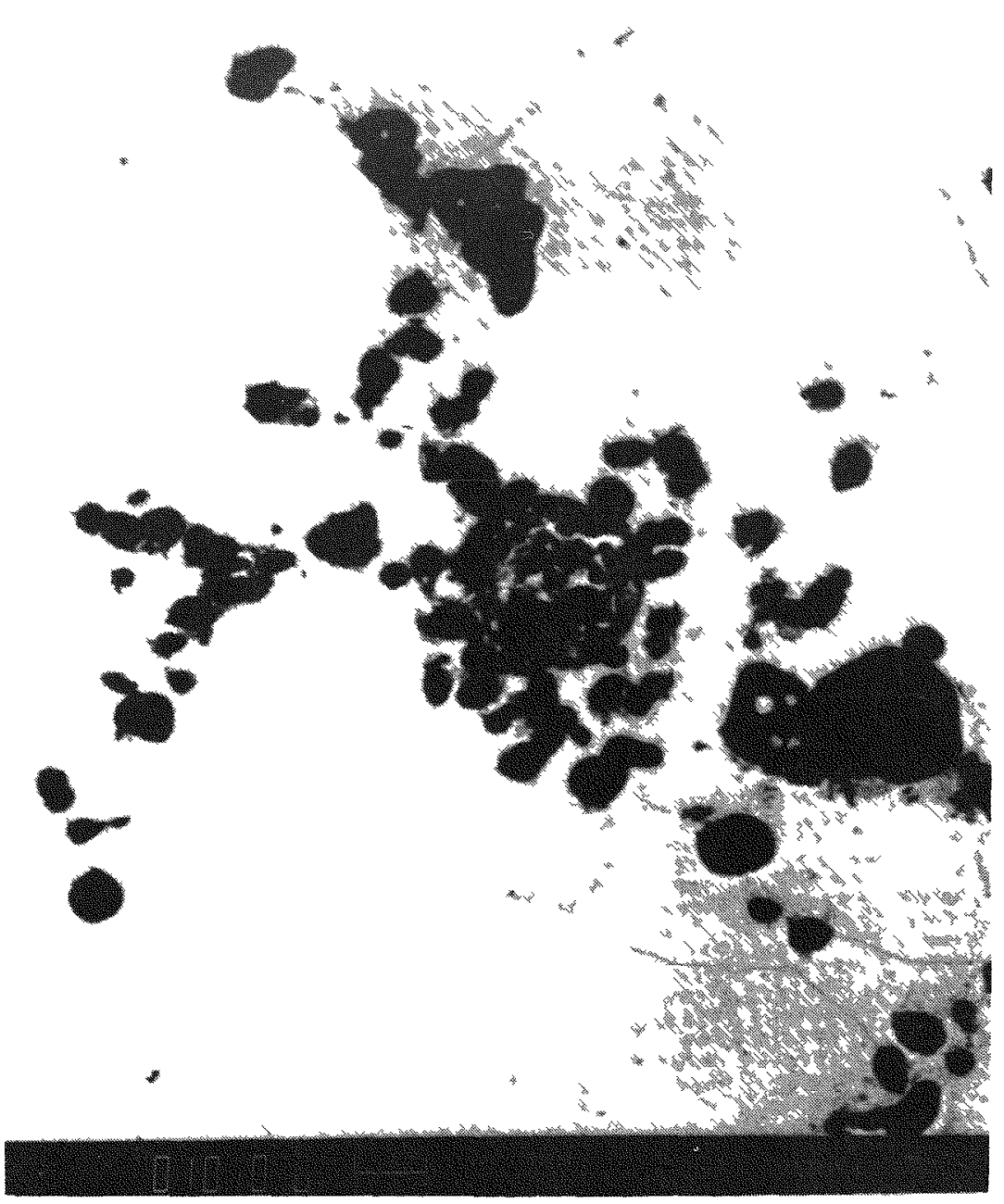

B.S.E. IMAGE, 500X

Fig. 13. Typical As-Cast Microstructure of Batch EFL-036 
grain boundaries using high contrast in the BSE mode were not successful for batches EFL-029 and EFL-031.

\section{MICRO-CHEMISTRY OF THE SAMPLES}

\section{A. SEM-EDX}

Energy dispersive $X$-ray spectroscopy (EDX) was performed on several of the samples using the SEM. Typical spectra from the globular phase and from the base material (or matrix) are shown in Fig. 14. These data show that the globular phase consisted primarily of $\mathrm{Zr}$ and that the matrix also contained a significant amount of $\mathrm{Zr}$. However, the largest peaks for $U$ and $\mathrm{Pu}$ were at 3.16 and $3.35 \mathrm{kev}$ and were too close together to separate without computer based deconvolution techniques that were not available for the shielded SEM. In EDX of random examples of the globular phase, a signifcant amount of $S i$ was found in the phase in a few cases. Although low atmic number elements (< atomic no. 10) can not be detected directly with EDX, variation in the X-ray intensity for $\mathrm{Zr}$ in the globular phase at various locations indicated that low atomic number elements were also present in the phase.

The layer on the surface of the sample from the bottom of the EFL-029 pin was also analyzed with the EDX. These data indicated that there were two dark gray phases present, which were high in $\mathrm{Zr}$, and a lighter gray phase with a $\mathrm{Zr}$ to $\mathrm{U}$ and $\mathrm{Pu}$ ratio similar to that of the matrix material as shown in Fig. 15. X-ray data 


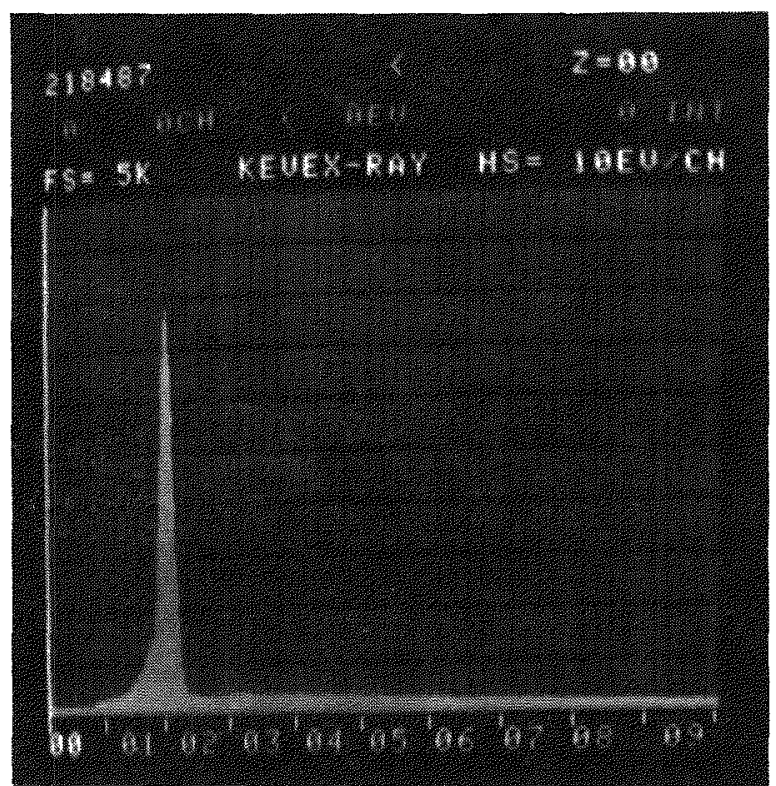

X-RAY SPECTRUM GLOBULAR PHASE

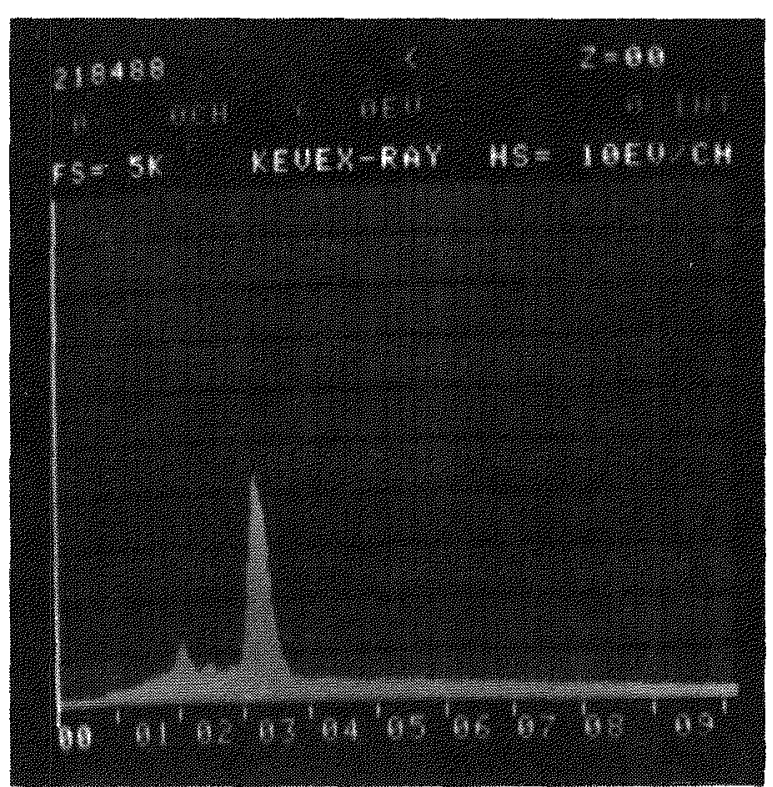

X-RAY SPECTRUM BASE MATERIAL

Fig. 14. Typical $X$-ray Spectra from the Globular Phase and Matrix of the Ternary Fuel; Near the Centerline of a Pin from Batch EFL-029 


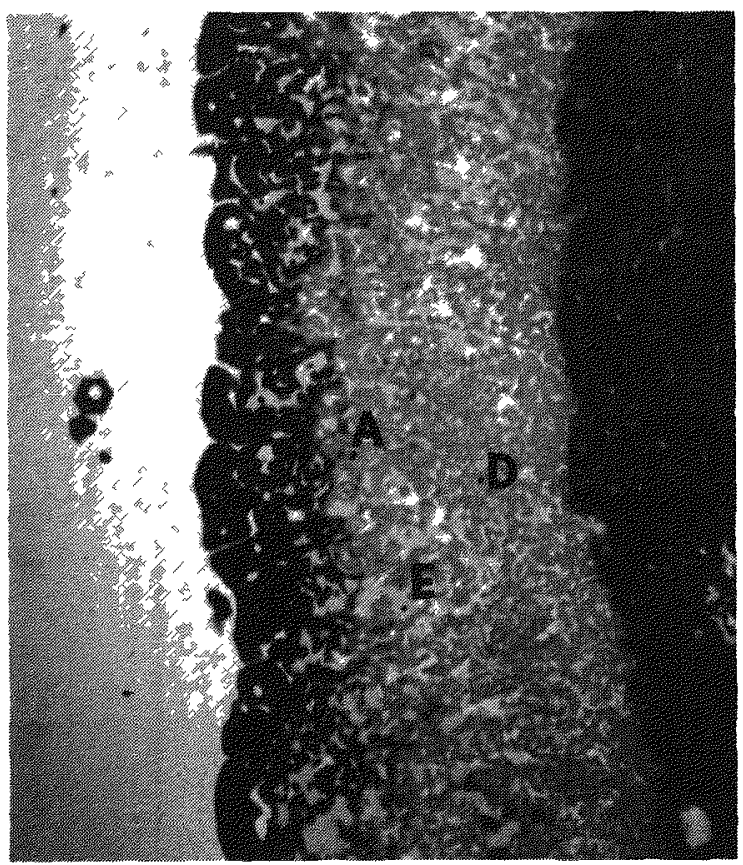

Location in

Micrograph

A

B

C

D

E $\frac{x-\text { Ray Intensity, Counts/s }}{\underline{U} \quad \underline{\text { Sr }}}$

$0.4 \quad 12.0 \quad 5.0$

$1.4 \quad 16.0 \quad 5.5$

$12.0 \quad 2.2 \quad 1.1$

$6.0 \quad 4.0 \quad 3.0$

$12.0 \quad 0.4$

Fig. 15. SEM EDX Data for the Surface Layer on a Sample from Batch EFL-029 
from a band about 15 microns wide in the matrix at the edge of the pin indicated $\mathrm{Zr}$ was depleted in this area.

\section{B. SAM Analys is of the Surface Layer}

The scanning Auger microprobe (SAM) was used to analyze the composition of the outer layer on the bottom sample from batch EFL-029. The SAM interogates the surface of a sample by detecting low energy electrons (Auger electrons) that are emmitted as a result of excitation of the sample by the electron beam. The SAM is capable of detecting elements with atomic numbers as low as 3 (Lithium). Each area that was examined was sputtered so that a clean surface was examined.

The results of analysis of the surface layer on the bottom sample from batch EFL-029 is shown in Fig. 16. These data show that the darker material adjacent of the fuel is $\mathrm{Zr}$ that contains between 12 and 18 wt $\% 0$ and 4 to 6 wt \% C. The light gray phases contain $\mathrm{Zr}$ and $\mathrm{Si}$ as well as oxygen and carbon. The medium gray phase on the outer edge of the layer has a composition simi$\operatorname{lar}$ to the fuel but contains a greater amount of oxygen (about 2 wt \%) than the fuel.

\section{SAM Analysis of the Globular Phase}

The SAM was used to examine inclusions in the bottom samples from batch EFL-029 and a bottom sample from pin VC-1-2. The data on inclusions from near the centerline and edge of the EFL-029 sample are given in Fig. 17. These results indicate the inclu- 


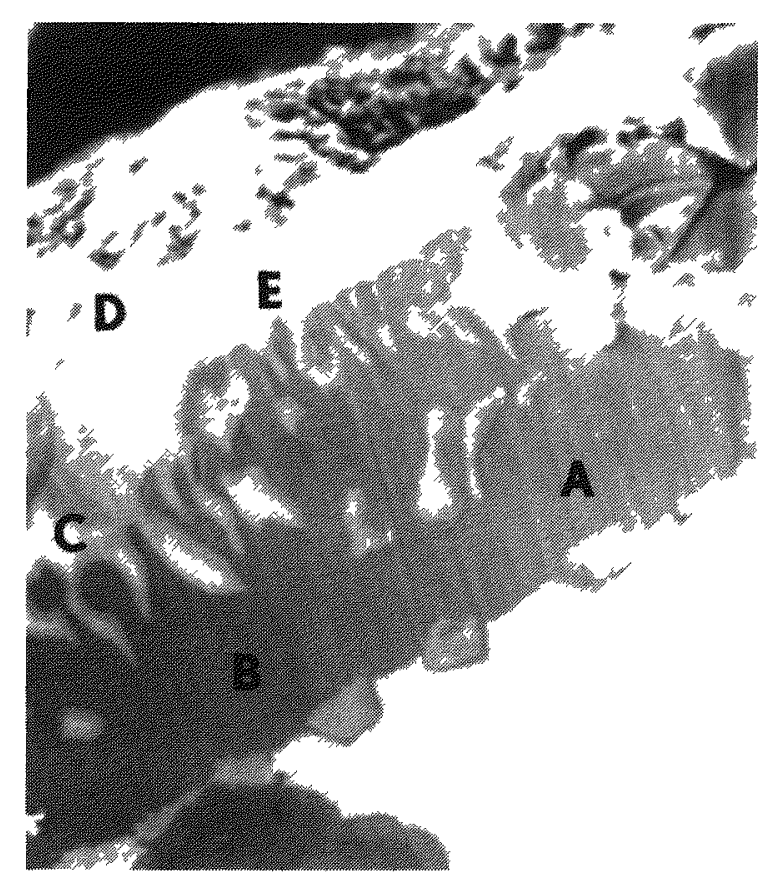

Location in Micrograph

A

B

C

D

E
U, Pu, Zr, Si, 0, C, N, $\frac{\text { Description }}{\text { Dark }} \frac{w t \%}{0} \frac{w t \%}{0} \frac{w t \%}{82} \frac{w t \%}{0} \frac{w t \%}{12} \frac{w t \%}{6} \frac{w t \%}{0}$ Dark Light Light Medium

$\begin{array}{ll}0 & 0\end{array}$

00

$0 \quad 0$

87

$0 \quad 0$

86 $\begin{array}{lllll}87 & 0 & 10 & 3 & 0\end{array}$

$\begin{array}{lllll}61 & 17 & 18 & 4 & 0\end{array}$

$\begin{array}{lllll}41 & 40 & 9 & 10 & 0\end{array}$

$\begin{array}{lllll}12 & 0 & 2 & 0 & 0\end{array}$

Fig. 16. SAM Data for the Surface Layer on a Bottom Sample from Batch EFL-029 


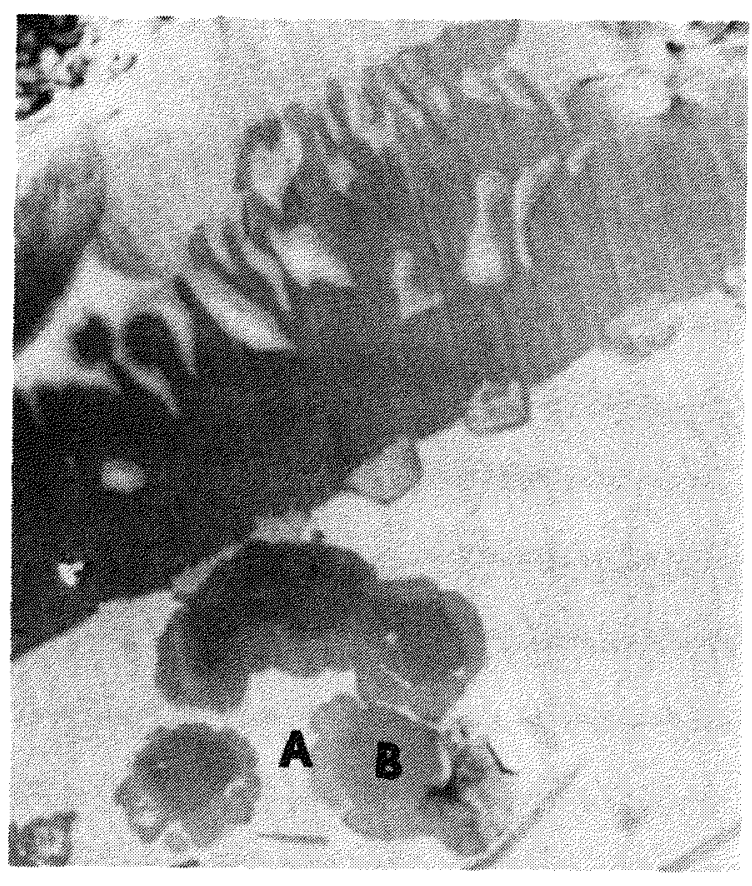

EDGE

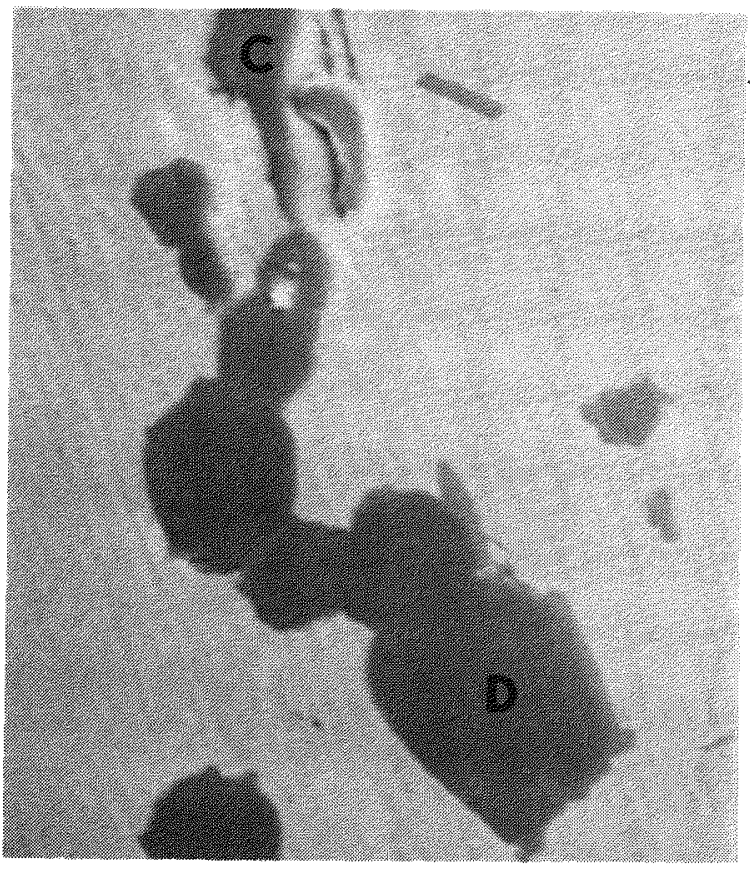

CENTER
Location in

Micrograph

A

B

C

D
U, Pu, Zr, Si, 0, C, N,

\begin{tabular}{|c|c|c|c|c|c|c|c|}
\hline Description & wt\% & $w t \%$ & wt\% & $w t \%$ & wt\% & $w t \%$ & $w t \%$ \\
\hline Dark & 0 & 0 & 78 & 0 & 5 & 16 & 1 \\
\hline Dark & 0 & 0 & 72 & 0 & 4 & 15 & 0 \\
\hline Dark & 0 & 0 & 80 & 0 & 4 & 16 & 0 \\
\hline Dark & 0 & 0 & 77 & 0 & 4 & 18 & 1 \\
\hline
\end{tabular}

Fig. 17. SAM Data for Inclusions in a Bottom Sample from Batch EFL-029 
sions consisted of $\mathrm{Zr}$ with small concentrations of 0 and $N$, but relatively lare amounts of $C$. These high $C$ concnetrations are considered suspect as it is unlikely that the atom ratio of $C$ to $\mathrm{Zr}$ would be greater than 1 (about 12 wt \% C). An inclusion near the OD of this sample had a darker center in the BSE image, indicating a change in composition. The SAM data indicated that the center of the inclusion contained a relatively high concentration of $\mathrm{Pu}(26$ wt \%) as well as high $0(5$ wt \%) and C (10 wt \%). The outer ring of the inclusion had a composition similar to the inclusions near the center of the sample ( $2 r 78$ wt \%, 05 wt \%, N 1 wt $\%$, and C 16 wt $\%$.

Results of SAM analyses of inclusions in a sample from the bottom of the VC-1-2 pin are given in Fig. 18. These data indicate that the inclusions near the center of the sample contained about 94 wt $\% \mathrm{Zr}, 3$ to 4 wt $\% 0,1$ wt $\% \mathrm{C}$ and 1 wt $\% \mathrm{~N}$. The inclusion near the $O D$ of the sample contained slightly less $\mathrm{Zr}$ and had higher concentrations of the interstitials. The needlelike inclusions in this sample contained $U$ and $P U$, but also had higher concetrations of $\mathrm{Zr}$ and 0 than the matrix $(\mathrm{Zr} 25 \mathrm{wt} \%$ and 01 wt \%). Analyses of the needle-like phase were not accurate because the needles were so narrow that the beam spilled over onto the matrix. The data do indicate the the needles were a separate phase that was high in $\mathrm{Pu}$ and $\mathrm{Zr}$. 


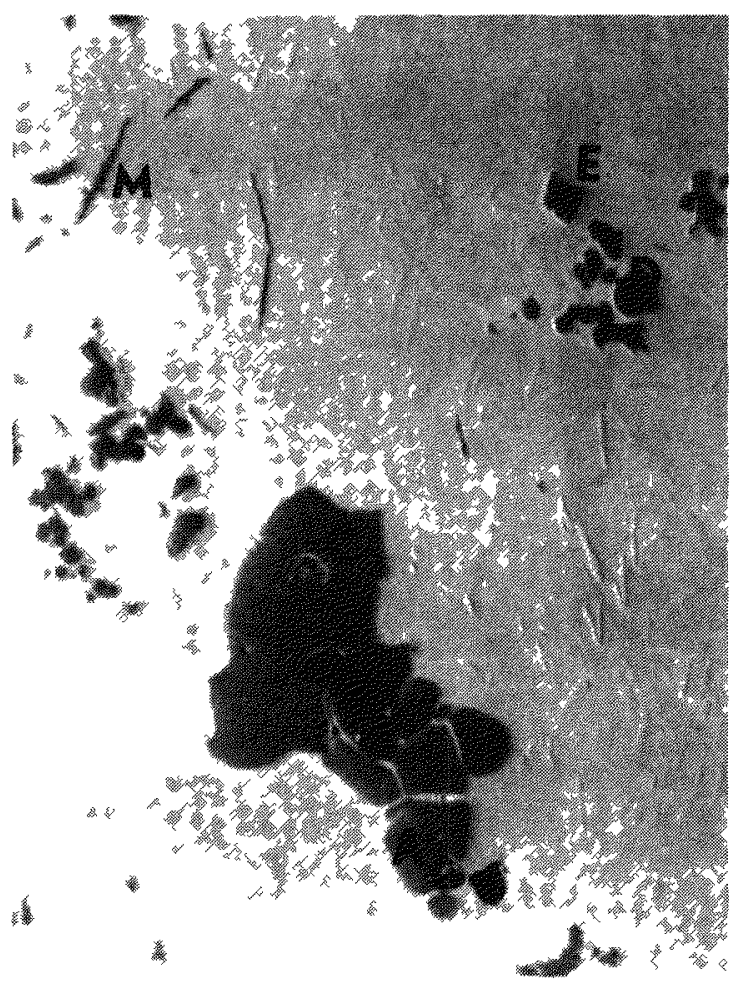

Near Edge

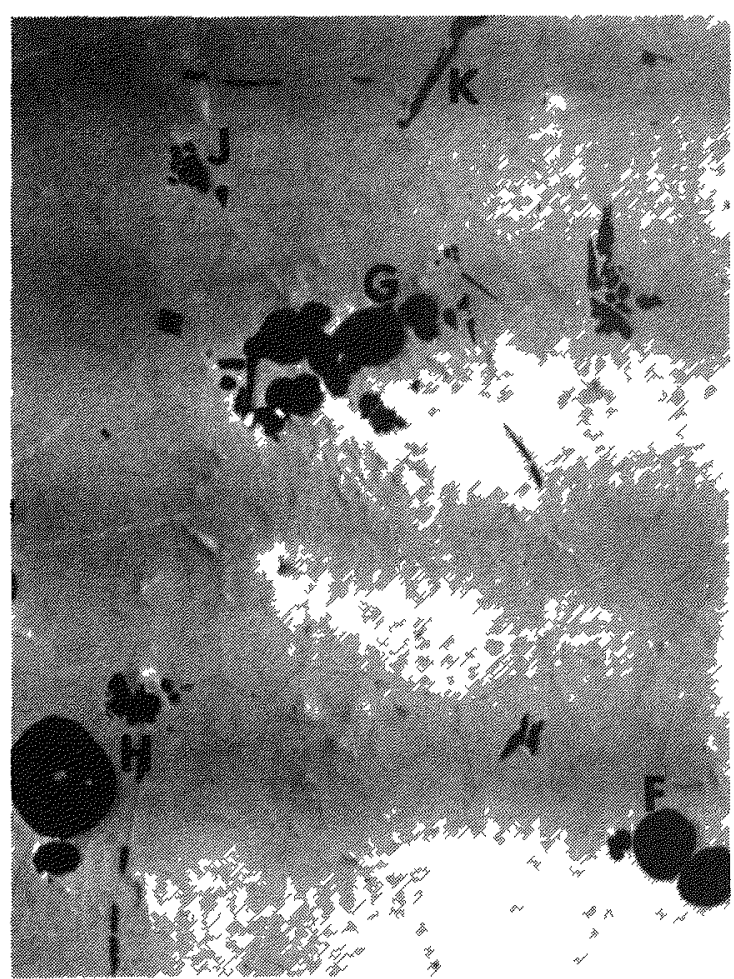

Center
Location in Micrography
Description

Near Edge
Near Edge
Near Edge
Near Edge
Near Edge
Center
Center
Center
Center
Needle
Needle

U, Pu, Zr, Si, O, C, N, wt\% wt\% wt\% wt\% wt\% wt\% wt\%

$\begin{array}{rrrllll}0 & 0 & 92 & 0 & 5 & 2 & 1 \\ 0 & 0 & 88 & 0 & 4 & 7 & 1 \\ 0 & 0 & 92 & 0 & 5 & 2 & 1 \\ 0 & 0 & 90 & 0 & 4 & 4 & 2 \\ 0 & 0 & 84 & 0 & 5 & 8 & 3 \\ 0 & 0 & 95 & 0 & 3 & 1 & 1 \\ 0 & 0 & 94 & 0 & 4 & 1 & 1 \\ 0 & 0 & 95 & 0 & 3 & 1 & 1 \\ 0 & 0 & 92 & 0 & 4 & 3 & 1 \\ 66 & 9 & 24 & 0 & 1 & 0 & 0 \\ 59 & 13 & 27 & 0 & 1 & 0 & 0\end{array}$

Fig. 18. SAM Data for Inclusions in a Bottom Sample from Pin VC-1-2 


\section{SAM Analys is of the Matrix}

The SAM was also used to analyze the matrix of a bottom sample from EFL-029 and VC-1-2. However, these results showed that the SAM has relatively poor sensitivity for $\mathrm{Pu}$, which resulted in very small peaks with relatively large errors possible for the $\mathrm{Pu}$ analysis. The results of the SAM analysis are normalized to $100 \%$, so errors in the $\mathrm{Pu}$ data could also influence the results for the other constituents. The average of all analysis on the matrix of the VC-1-2 sample was: $\operatorname{Zr} 10.1 \mathrm{wt} \%, U 79.0 \mathrm{wt} \%$, and $\mathrm{Pu} 10.8$ wt \%. The average of all analyses on the matrix of the EFL-029 sample was: $\operatorname{Zr} 6.6$ wt \%, U 86.0 wt \%, and Pu 7.5 wt \%. The data from the EFL-029 sample also showed a trend of lower $\mathrm{Zr}$ content near the edge of the sample as compared to its center. The lack of agreement in the average values for both of the samples for $\mathrm{Pu}$ and the low average value for $\mathrm{Zr}$ for the EFL-029 sample indicate that the SAM does not provide reliable microchemical data for the matrix of these samples.

\section{DISCUSSION}

The microstructural and micro-chemical characterization of samples of U-Pu-Zr fuel has shown several features that were common to all of the samples. These features include a globular phase that has a high $\mathrm{Zr}$ content, a generally featureless matrix (except at higher Pu contents), and a surface layer that is higher in interstitial impurities than the matrix.

Micro-chemical analysis of the high $\mathrm{Zr}$ globular phase has 
shown that it contains varying amounts of oxygen, carbon, and nitrogen. In generar, the amount of oxygen and carbon present in the globular phase corresponds to oxygen stabilized alpha zirconium $\mathrm{Zr}(0)$ and $\mathrm{ZrC}$. These $\mathrm{Zr}$-compounds are very stable chemical$7 y$, and therefore, the amount of the material would not be expected to change significantiy as a result of heat treatment unless additional sources of the interstitual elements were present. This behavior is supported by the fact that the $\mathrm{Zr}$-rich phase did not change significantly during the bonding or heattreating of these samples. It appears that the second phase was formed during and before the casting operation. It is likely that any interstitial impurities that were present in the feed materials would be gettered by the $\mathrm{Zr}$ during the casting operation. In addition, during the heating of the charge to the casting temperature some additional carbon would be picked-up from the graphite crucible. The $s i$ in some of the inclusions and in the surface layer on the samples indicates that additional oxygen was picked-up from the vycor molds and from the zirconia wash on the molds during the casting operation. The greater amount of the $\mathrm{Zr}$-rich phase and a relatively high Si content in the EFL-031 batch correlates with a greater amount of reaction during the casting operation as a result of a higher casting temperature for that casting batch. 
The fact that grain boundaries were discernible in the EFL-036 and $V C-1-2$ samples and not in the EFL-029 and -031 samples indicates that the $\mathrm{Pu}$ content of the alloy has an influence on the as-cast structure of the matrix. The structures of the EFL -029 and the EFL-036 samples that were heat treated during a compatibility test were significantly different than the as-cast structures as shown in Fig. 4. However, a discussion of the microstructure of the heat treated samples is beyond the scope of this characterization.

This characterization showed that the SAM was useful in analyzing for the low atomic number elements that were present in the globular phase and in the surface layer. The low sensitivity of the instrument for $\mathrm{Pu}$ results in questionable results for analysis of the fuel matrix. Either electron microprobe analysis (X-ray wavelength dispersive analysis) or analysis with a SEM with computer capablility to deconvolute the energy dispersive results should be capable of providing micro-chemical analysis of the matrix. Electron microprobe analys is will be performed on these samples and reported at a later date.

\section{CONCLUSIONS}

The characterization of the current casting batches of the U-Pu-Zr fuel as well as samples from and "old" pin has shown that second phase in the as-cast structure is $\mathrm{Zr}$ that is probably stabilized in the alpha phase with the interstitial elements $0, C$, and N. The amount of this phase appears to be stable during 
bonding (about $2 \mathrm{~h}$ at $500 \mathrm{C}$ ) and during heat treating for up to $300 \mathrm{~h}$ at $750 \mathrm{C}$. The amount of this phase that is present appears to depend on the casting parameters as the higher temperature during the casting of EFL-031 appears to have resulted in a greater amount of the Zr-rich phase. Based on the apparent stability of the Zr-rich phase, no change in the irradiation performance of the fuel from these casting batches would be expected. However, it may be prudent to monitor the irradiation performance of fuel pins from these batches separately rather than lumping them into a single category of 8 wt \% Pu pins.

Al1 of the samples, including those for the VC-1-2 pin, exhibited a surface layer. This layer consisted mainly of $\mathrm{Zr}$ that contained relatively high amounts of 0 and a lesser amount of $C$. In most cases material with a composition similar to the fuel matrix, but with higher 0 content was also present in the outer band of the layer. The surface layers were thicker on samples from the bottom of the castings than those from the top. The surface layers appear to result from interaction between the melt and the mold (and the mold wash) during the casting operation. The bottom of the casting remains hot for a longer time than the top during the casting operation so has a longer time to react with the mold.

Micro-chemical data on the composition of the matrix has not been accurate as a result of the instruments being insensitive to Pu. Future examinations should correct this deficiency. 
This examination found no differences in the current castings and the "old" fuel pin that would be expected to result in differences in the irradiation performance of the fuel.

\section{REFERENCES}

1. W. F. Murphy, et. a1., "Postirradiation Examination of U-PU-Zr Fuel Elements Irradiated in EBR-II to 4.5 Atomic Percent Burnup, "ANL-7602, November 1969.

2. A. B. Shuck, et. a1., "Fabrication of EBR-II Core I Fuel Rods," ANL-6274, 1967. 